\title{
On the impact of high-resolution, high-frequency meteorological forcing on Denmark Strait ocean circulation
}

\author{
T. W. N. Haine, ${ }^{a *}$ S. Zhang, ${ }^{b}$ G. W. K. Moore ${ }^{\mathrm{b}}$ and I. A. Renfrew ${ }^{\mathrm{c}}$ \\ a Earth and Planetary Sciences, The Johns Hopkins University, Baltimore, Maryland, USA \\ ${ }^{\mathrm{b}}$ Department of Physics, University of Toronto, Canada \\ c School of Environmental Sciences, University of East Anglia, Norwich, UK
}

\begin{abstract}
This paper quantifies and discusses the impact of high-resolution, high-frequency atmospheric forcing on the ocean circulation in the vicinity of the Denmark Strait. The approach is to force a $2 \mathrm{~km}$ resolution regional ocean circulation model with atmospheric states from reanalysis products that have different spatial and temporal resolutions. We use the National Center for Environmental Prediction global reanalysis data $\left(2.5^{\circ}\right.$ resolution, 6-hourly output) and a specially configured regional atmospheric model (12 km resolution, hourly output). The focus is on the month-long period in winter 2007 during the Greenland Flow Distortion Experiment. Diagnostics of upper-ocean currents and mixing are sensitive to the small-scale variability in the high-resolution regional atmospheric model. The hydrographic state of the ocean model is insensitive over the month-long experiments, however. Both sea ice and the fluxes of volume, heat, and freshwater across the east Greenland shelf break and through the Denmark Strait show a moderate response to the high-resolution atmospheric forcing. The synoptic-scale atmospheric state has a large role in controlling sea ice too, while internal ocean dynamics is the dominant factor controlling the flux diagnostics. It is the high spatial resolution, not the temporal resolution, that causes these effects, with $\mathrm{O}(10 \mathrm{~km})$-scale features being most important. The sea-level wind field is responsible, with the other atmospheric fields playing relatively minor roles. Copyright (c) 2009 Royal Meteorological Society
\end{abstract}

KEY WORDS GFDEx; air/sea interaction; NCEP reanalyses; MM5

Received 15 January 2009; Revised 22 July 2009; Accepted 28 July 2009

\section{Introduction}

The Denmark Strait, between Greenland and Iceland, is a vital conduit between the Arctic and the North Atlantic Oceans. The equatorward tranport of dense polar water through the strait comprises a key part of the deep limb of the global meridional overturning circulation (MOC) in the ocean (Dickson et al., 2008). This transport includes spilling of so-called Denmark Strait Overflow Water across the $600 \mathrm{~m}$ deep saddle. It also includes movement of fresh, cold water - and sea ice - along and off the $200 \mathrm{~km}$ wide east Greenland continental shelf (Bacon et al., 2008). These transports, and the ocean circulation in the Irminger Sea, are subjects of longstanding importance in oceanography. They also have growing importance in climate dynamics because of their link to the MOC (Haine et al., 2008).

The atmospheric circulation of the North Atlantic region is also strongly influenced by Greenland. In particular, the location and strength of mesoscale weather systems in the Denmark Strait and Irminger Sea are largely controlled by the high Greenland ice sheet. 'Tip jets', 'reverse tip jets', 'barrier winds', and 'polar

\footnotetext{
${ }^{*}$ Correspondence to: Thomas Haine, 329 Olin Hall, 3400 N. Charles Street, Baltimore, MD, 21218, USA.

E-mail: thomas.haine@jhu.edu
}

lows' are characteristic atmospheric flow phenomena near southeast Greenland (Moore and Renfrew, 2005). To describe the role that Greenland plays in distorting atmospheric flow in these ways, the Greenland Flow Distortion Experiment (GFDEx) was conducted between 21 February and 10 March 2007 (Renfrew et al., 2008). Meteorological observations were made over the Irminger Sea, Denmark Strait, and the Iceland basin with an instrumented aircraft flying out of Keflavik, Iceland. Significant effort was made on these flights to observe the sea-level atmospheric state during periods of intense air/sea interaction.

Near Cape Farewell (the southern tip of Greenland), the mesoscale atmospheric flow is known to have a substantial impact on the ocean circulation (Pickart et al., 2003) and hydrography (Våge et al., 2008). Less is known about the impact of strong atmospheric forcing on the ocean in the northern Irminger Sea and Denmark Strait, however. In this contribution we explore the question in detail. The aim is to document the influence of highresolution, high-frequency meteorological forcing on the ocean in this region during the GFDEx field campaign. The approach is to force a $2 \mathrm{~km}$-resolution regional ocean model of the Denmark Strait and environs with atmospheric reanalysis data of different types. We use the popular National Center for Environmental Prediction 
(NCEP) global reanalysis data (Kalnay et al., 1996). We also use a much higher-resolution regional atmospheric simulation that is specially configured for the North Atlantic during GFDEx (based on the fifth-generation Mesoscale Model, MM5; Grell et al., 1995). The impact of these forcing products on several diagnostics of ocean circulation, hydrography, and sea ice are presented and explained. The impact of specific barrier wind and polar low events are discussed in detail.

The article is unique in a number of ways. First, the ocean model is, to our knowledge, the best-resolved, most-realistic simulation of the Denmark Strait and Irminger Sea circulation to date. Likewise, the highresolution atmospheric model is among the best-resolved simulations of the sub-polar North Atlantic circulation yet reported. By focussing on the GFDEx observing period, there is also an unprecedented opportunity to assess the fidelity of the high-resolution atmospheric model during times of intense wintertime high-latitude storms (Renfrew et al., 2009). The emphasis here is on quantifying the effect of this small-scale, short-period weather on the oceanic state.

The layout of the paper is straightforward. The ocean and atmosphere models, and the numerical experiments, are described in section 2 , the results are presented and discussed in section 3 , and the concluding discussion is in section 4.

\section{Methods}

\subsection{High-resolution ocean circulation model}

The numerical ocean circulation model used here is based on the MITgcm (Marshall et al., 1997). The MITgcm is configured to solve the Boussinesq incompressible Navier-Stokes equations in a rotating spherical coordinate system. The vertical grid uses the $r^{*}$ coordinate (Adcroft and Campin, 2004), with a nonlinear free surface (Campin et al., 2004), and represents bottom bathymetry using variable-thickness bottom cells (Adcroft et al., 1997). Advection of temperature and salinity is computed using a third-order direct space-time flux-limited scheme while the equation of state is based on Jackett and McDougall's (1995) paper. The model includes the Large et al. (1994) planetary boundary layer (PBL) parametrization to capture the effects of unresolved turbulent processes in the ocean. The Leith (1968) parametrization for viscous dissipation from unresolved scales is also applied, which aims to cascade enstrophy to the grid-scale by computing a viscosity proportional to the horizontal gradient of the relative vorticity. Sea ice thermodynamics are represented using the Hibler (1980) two-category model, which simulates sea ice concentration and thickness fields, and snow is represented by the Zhang et al. (1999) model. Sea ice dynamics are represented using the viscous-plastic Zhang and Rothrock (2000) algorithm. We apply the hydrostatic assumption; tests using the nonhydrostatic version of the MITgcm give almost indistinguishable results for the fields shown here.
The horizontal grid consists of $540 \times 360$ cells in longitude and latitude with a variable spacing that ranges from $1.7 \mathrm{~km}$ in the centre of the domain to $12 \mathrm{~km}$ at the edges. There are 97 levels in the vertical which are $2 \mathrm{~m}$ thick at the surface and increase to $200 \mathrm{~m}$ thick at $3300 \mathrm{~m}$. There are 58 levels in the upper $1000 \mathrm{~m}$ and 87 levels in the upper $2000 \mathrm{~m}$. The bathymetry is interpolated from the International Bathymetric Chart of the Arctic Ocean which covers the Arctic at $2.5 \mathrm{~km}$ resolution (Jakobsson et al., 2000); an early configuration of the model used ETOPO2 data, but some obvious problems were present on the Greenland shelf. The explicit diffusivity for heat and salt is zero, the side walls have free-slip boundary conditions, and the bottom has a no-slip condition with a quadratic drag law using a coefficient of 0.001 .

The model is configured in a regional domain with walls at the open boundaries. (Figure 1(a); the domain spans $\left.60-70^{\circ} \mathrm{N}, 43.4-10.1^{\circ} \mathrm{W}\right)$. The problem of how to handle boundaries in regional models is challenging, and there is no truly satisfactory approach. A coarser version of the current model successfully uses open boundary conditions at the edges (Lea et al., 2006), but early tests with the present resolution led to divergence of the elliptic solver with these conditions. Our use here of a telescoping grid, a sponge layer (see below), and walls at the open boundaries has the advantage of being simple and robust. We also note that typical trajectories of surface Lagrangian particles cross less than half of the domain during the experiments. Most fluid is therefore not in material contact with the boundaries over this period. The solution structure in the Denmark Strait and northern Irminger Sea - the main region of interest is probably not strongly influenced by the walls at the open boundaries for these reasons. Definitive evidence must wait for further experiments with larger domains and larger computing resources, however.

Initial conditions for temperature and salinity are taken from a time average of the hydrographic data at the International Council for the Exploration of the Sea database. The model fields are also relaxed to these data with a time-scale of 5 days within a characteristic distance of 10 grid points from the open boundaries. The initial velocity field is zero. Forcing of the model by air/sea interaction is achieved by computing fluxes using bulk formulae and estimates of the atmospheric state interpolated to the MITgcm grid. We avoid using the turbulent fluxes computed from the MM5 and NCEP meteorological reanalyses themselves because of known deficiencies in the surface flux algorithms used in these models (Pagowski and Moore, 2001; Renfrew et al., 2002). Instead, the fluxes are computed from the ocean-model state using a version of the Large and Pond $(1981,1982)$ bulk aerodynamic formulae. A nine-month-long spin-up calculation (starting 1 June 2006) is used to provide initial conditions for the experiments reported below, forced by the 6-hourly global NCEP reanalyses. The experiments themselves use atmospheric state estimates taken from the 6-hourly NCEP data and/or a custom high-resolution hourly reanalysis using the MM5 model that is described in section 2.2 below. 

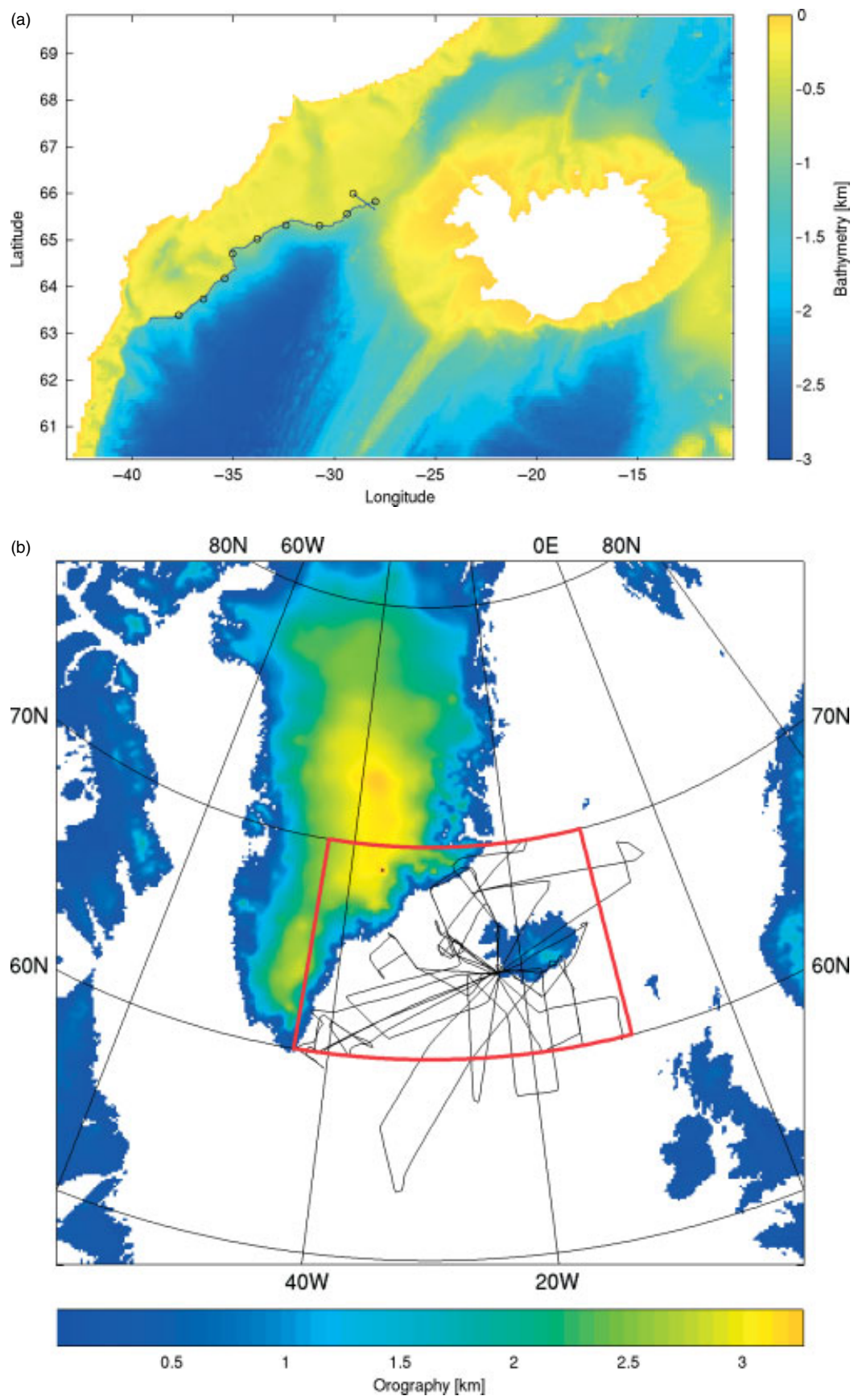

Figure 1. (a) Ocean circulation model domain, bathymetry $(\mathrm{km})$, and transects used to compute fluxes in Figures 9-10. The shelf-break transect follows the $550 \mathrm{~m}$ depth contour, and the Denmark Strait section is at the location of the OVERFLOW-73 mooring array (the Denmark Strait South (DSS) section; Ross, 1977). Small circles are separated by $100 \mathrm{~km}$. (b) Model domain of the high-resolution regional atmospheric circulation model (MM5) showing orography $(\mathrm{km})$ and the flight tracks of the GFDEx campaign.

A comprehensive assessment of the fidelity of the ocean model compared to observations is beyond the scope of this article. Two issues make the comparison challenging. First, at scales of $\mathrm{O}(1-10) \mathrm{km}$ the observations are very sparse, and almost non-existent in winter (the time of interest here). At scales of $\mathrm{O}(100) \mathrm{km}$ the model solutions look realistic, because the flow is controlled by the density field, which is realistic by virtue of the climatological initial condition. Second, the model solutions are turbulent and chaotic, and agreement within instrumental error between the simulation and measurement should not be expected. The difficult question then arises of what qualifies as sufficient agreement. One approach is to perform data assimilation and directly attempt to reconcile the model/data differences within all the appropriate uncertainties. This approach is under way, but will be reported elsewhere.

Notwithstanding these issues, the model Denmark Strait overflow variability (Figure 12 below; section 3.5) is consistent with the short Ross (1977) mooring-array data and satellite imagery (in particular, Figure 7 of Bruce, 1995). Moreover, Käse et al. (2003) show that the regional Denmark Strait model of Käse and Oschlies (2000) 'is able to replicate most of the salient features 
of the observed Denmark Strait overflow'. The Käse and Oschlies (2000) model used a $4 \mathrm{~km}$ resolution grid, and an ideal configuration that excluded air/sea forcing. The current model, with higher resolution, realistic hydrography, and realistic forcing, therefore likely represents Denmark Strait circulation adequately, in particular because our focus is on the impact of different air/sea forcing products. More detailed comparison of the sea-surface circulation with observations appears in section 3.2 below, but a full assessment of the model realism is postponed to future work.

\subsection{High-resolution meteorological reanalysis}

The Pennsylvania State University-National Center for Atmospheric Research fifth-generation Mesoscale Model (MM5) version 3.7 is used for the high-resolution meteorological simulations (Grell et al., 1995). The main features of this MM5 configuration that are relevent here are:

(1) The Kain and Fritsch (1993) convective parametrization with shallow convective effects,

(2) The Goddard microphysics explicit moisture scheme with graupel/hail as an additional variable (Tao et al., 1989; Tao and Simpson, 1993),

(3) A non-local Medium-Range Forecasts (MRF) PBL scheme including up-gradient transport of heat and moisture under unstable condition (Hong and Pan, 1996),

(4) A Dudhia-type radiation cooling scheme including the effects of modelled clouds (Zängl, 2002),

(5) A multi-layer soil model to predict land surface temperatures by using the surface energy budget equation (Dudhia, 1996), and

(6) A polar physics modification that includes the effects of sea-ice fraction and surface fluxes over sea ice (Bromwich et al., 2001; Cassano et al., 2001), which has been added to the Eta PBL and MRF PBL schemes in MM5 version 3.7.

The MM5 model is formulated using a staggered horizontal grid with a vertical $\sigma$-coordinate system that is defined in terms of pressure. A regional domain is used in the simulations reported here. The domain is centred at $67^{\circ} \mathrm{N}, 30^{\circ} \mathrm{W}$ longitude with a uniform grid size of $12 \mathrm{~km}$ (Figure 1(b)), and covers Baffin Island, the Norwegian Sea, Labrador Sea, and almost all of Greenland. The horizontal grid is $340 \times 320$ cells using a polar stereographic projection. In the vertical, MM5 uses terrain-following $\sigma$-coordinates, with the pressure at the $\sigma$-levels determined from a reference state that is estimated using the hydrostatic equation and a standard lapse rate. There are $25 \sigma$-levels that are unevenly spaced with 10 levels in the lowest $1 \mathrm{~km}$. The surface layer is defined at an altitude of about $10 \mathrm{~m}$. The model top is set at $50 \mathrm{hPa}$ with a radiative upper-boundary condition to minimize the reflection of internal gravity waves.

NCEP final analyses (FNL) data were used to initialize the MM5 model and to provide lateral boundary conditions during the simulations (http:// wwwt.emc.ncep.noaa.gov/gmb/para/parabout.html gives details on FNL data). The 6-hourly $1^{\circ}$-resolution surface and upper-air analysis data are interpolated onto the MM5 model grid. In addition, the $25 \mathrm{~km}$ near-real-time Special Sensor Microwave/Imager (SSM/I) Equal-Area Scalable Earth (EASE) Grid daily global ice concentration and snow extent data from the National Snow and Ice Data Center and the $6 \mathrm{~km}$ Operational Sea Surface Temperature and Sea Ice Analysis (OSTIA) sea surface temperature were used for the lower-boundary conditions (Stark et al., 2007). The model is re-initialized at 1200 UTC every day during the GFDEx period and integrated for $36 \mathrm{~h}$. To allow a model adjustment, we discard the first $12 \mathrm{~h}$ of model output for each run and use the final $24 \mathrm{~h}$ of the simulation to force the ocean circulation model.

GFDEx dropsonde data were posted rapidly to the Global Telecommunications System during the field campaign. Therefore these data were included in the data assimilation cycles used for the NCEP FNL product, and hence the MM5 hindcasts used here (Table 1 of Renfrew et al., 2008). No flight-level data were available in time for operational assimilation, however.

A validation of the MM5 and NCEP data against lowlevel aircraft observations from the GFDex field campaign has been carried out by Renfrew et al. (2009). The observations used consist of about 150 data points spread over $6 \mathrm{~d}$ during February and March 2007, with each comparison point derived from a 2 min mean of flightlevel measurements, thus equivalent to a spatial mean over about $12 \mathrm{~km}$. This is the same spatial scale as the MM5 grid. The observations were taken $30-50 \mathrm{~m}$ above sea level and adjusted to standard meteorological heights for the comparison. They were made mainly during coldair outbreaks and moderate to high wind speeds, so are associated with strong atmospheric forcing conditions, i.e. high surface momentum and heat fluxes. In general the MM5 hindcasts compare well to the observations, on a par with other high-resolution analyses, and significantly better than the coarser-resolution NCEP global reanalyses. For example, the $10 \mathrm{~m}$ mean wind speeds were $17.3,16.3$, and $14.2 \mathrm{~m} \mathrm{~s}^{-1}$ for the observations, MM5, and NCEP global products respectively; while the correlation coefficients (and r.m.s. errors) between the observations and the MM5 and NCEP data were $0.83\left(2.2 \mathrm{~m} \mathrm{~s}^{-1}\right)$ and $0.62\left(5.0 \mathrm{~m} \mathrm{~s}^{-1}\right)$ respectively. One weakness in the MM5 wind field was a low slope (0.7) in a linear regression against the observations. This was caused by occasional underestimations of the highest wind speeds (greater than $20 \mathrm{~m} \mathrm{~s}^{-1}$ ) and also a poor representation of a wake region during the polar low case (discussed in more detail in section 3.3 below). The comparison also found a small warm bias $\left(+1.7^{\circ} \mathrm{C}\right)$ in the near-surface air temperature, caused by a similar-sized bias in the OSTIA sea-surface temperature input data. This small bias does not significantly affect the heat fluxes used to force the ocean model, as it affects both air and sea temperatures. The MM5 relative humidity compares rather poorly to the observations; there appears little skill in the model for this variable. Although this is a concern for users of the MM5 model, 
Table I. Numerical experiments.

\begin{tabular}{lccccc}
\hline Expt. & 1 & 2 & 3 & 4 & 5 \\
\hline GFDL name $^{a}$ & run5h & run5i & run5g & run5k & run51 \\
Wind forcing $^{c}$ & MM5 & NCEP & NCEP & MM5 $^{b}$ & NARR $^{c}$ \\
Other forcing & MM5 & MM5 & NCEP & MM5 $^{b}$ & NARR $^{c}$ \\
\hline
\end{tabular}

${ }^{a}$ Refers to the directories at the Geophysical Fluid Dynamics Laboratory supercomputer centre; output from the experiments are available by contacting the first author.

${ }^{b}$ Using 6-hourly, not hourly, MM5 fields (section 3.6).

${ }^{c}$ North American Regional Reanalysis data (section 3.7).

it is not that important for the latent heat flux forcing fields, as these are a function of specific humidity which is strongly governed by temperature.

It is worth noting that Renfrew et al. (2009) conclude that the NCEP Global reanalyses are 'simply too coarse to adequately resolve the mesoscale flow structures observed'. They do capture the basic synoptic-scale features, but neither the details, nor the peak magnitudes, are represented, particularly in the surface wind field (Figure 2). Like MM5, the NCEP model also suffers from lack of skill for relative humidity.

\subsection{Numerical experiments}

Three main numerical experiments are performed to test the impact of high-resolution atmospheric forcing fields on the Denmark Strait ocean circulation. The experiments are summarised in Table I: Expt. 1 is forced with the $12 \mathrm{~km}$ hourly MM5 data. Expt. 3 is forced with the $2.5^{\circ}$ $(275 \mathrm{~km})$ resolution, 6-hourly NCEP reanalysis data, and Expt. 2 is identical to Expt. 1, except that the MM5 surface wind estimates are replaced by the equivalent NCEP data. Two other experiments involving 6-hourly MM5 data and North American Regional Reanalysis data are also briefly reported in sections 3.6 and 3.7. The period of interest starts on 13 February and ends on 17 March 2007; the 12 flights during the GFDEx campaign were between 21 February and 10 March of that year (Figure 1(b) shows the flight tracks, and Figure 8 below the flight times; Renfrew et al., 2008, give more details). Moore et al. (2009) present a GFDEx climatology that shows synoptic conditions resulted in persistent barrier flow throughout much of the experimental period.

\section{Results}

We present and discuss the results of the numerical experiments by focussing on various diagnostics in turn.

\subsection{Time-averaged quantities}

First, we examine some mean air/sea forcing diagnostics. Table II shows $10 \mathrm{~m}$ wind components, air/sea heat fluxes and precipitation rate data from the whole experimental period. The peak wind speed components of the MM5 data (Expt. 1) substantially exceed the NCEP values
Table II. Summary of atmospheric forcings used in the numerical experiments.

\begin{tabular}{|c|c|c|c|}
\hline Diagnostic & Expt. 1 & Expt. 2 & Expt. 3 \\
\hline Peak zonal $10 \mathrm{~m}$ wind $^{a}$ & 40 & 27 & 27 \\
\hline Peak meridional $10 \mathrm{~m}$ wind ${ }^{a}$ & 32 & 26 & 26 \\
\hline Peak precipitation rate ${ }^{b}$ & 4.0 & 4.0 & 0.75 \\
\hline Mean precipitation rate ${ }^{b}$ & 0.060 & 0.060 & 0.046 \\
\hline Mean air/sea heat flux ${ }^{c}$ & 170 & 164 & 161 \\
\hline
\end{tabular}

(Expt. 3), by $25-50 \%$. The peak precipitation rate is also five times higher, although the mean rate is only $30 \%$ higher. The mean air/sea heat fluxes over the entire experiment - a significant cooling - are similar, however; the MM5 data are 6\% higher than the NCEP data, most of which is accounted for by the stronger MM5 winds (cf. Expts. 2 and 3 in Table II).

Table III shows corresponding results from the ocean circulation model for various global diagnostics. Over the whole period of the numerical experiments, the timeaveraged peak currents using the MM5 data (Expt. 1) exceed those forced by the NCEP data (Expt. 3) by 20$30 \%$. The peak vertical current speed is actually reduced (by 20\%) in Expt. 1 using the MM5 data, but most of this difference is not due to the weaker NCEP winds (cf. Expts. 2 and 3). The kinetic energy is higher in Expt. 1 than in Expt. 3 (by 35\% at peak and 13\% in the mean), which is attributable to the $10 \mathrm{~m}$ wind field. Similarly, the (barotropic) potential energy is $14 \%$ higher in Expt. 1. The range of sea-surface height is $43 \%$ higher using the MM5 forcing data, and the (vertical) relative vorticity range is $20 \%$ higher.

All of the above-mentioned diagnostics concern the ocean velocity fields directly, or are closely related. Table III also shows some global results for thermodynamic fields, which have much longer intrinsic timescales than dynamical quantities. For mean temperature and salinity, there is no difference between the three experiments. There are slight changes in the absolute ranges of these quantities, but they are also very small.

\subsection{Barrier wind case}

Next, we focus on a particular day, 9 March 2007, when a strong barrier wind was present in the Denmark Strait and the northern Irminger Sea. Figure 2 shows the forcing data used in Expts. 1 and 3 on that day. The synoptic situation at this time is a southeasterly surface-intensified barrier wind in the Denmark Strait associated with a cyclone over Iceland moving slowly to the north east. The peak wind speed in the MM5 data is $28 \mathrm{~m} \mathrm{~s}^{-1}$ (54 knots; Beaufort Force 10, storm) compared to $22 \mathrm{~m} \mathrm{~s}^{-1}$ (43 knots; Beaufort Force 9, strong gale) in the NCEP data. This difference is clear in Figure 2(a) and (b), and the more detailed structure in the MM5 data is striking. The surface air temperature fields are 
(a)

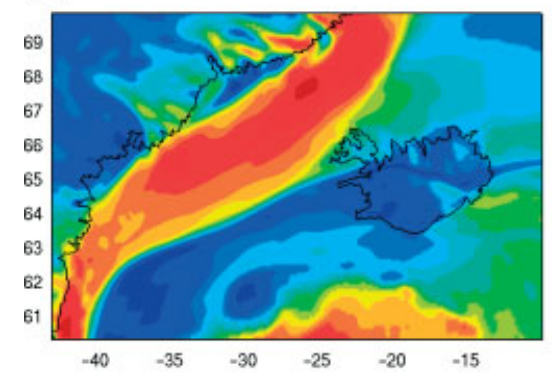

(d)

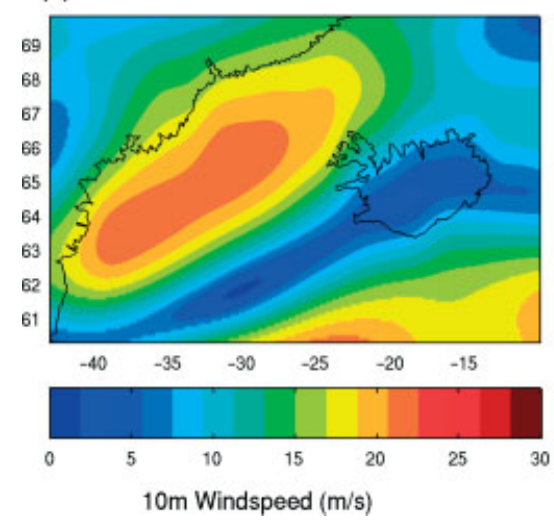

(b)

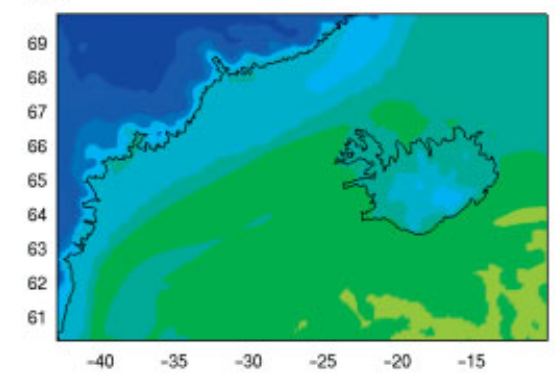

(e)

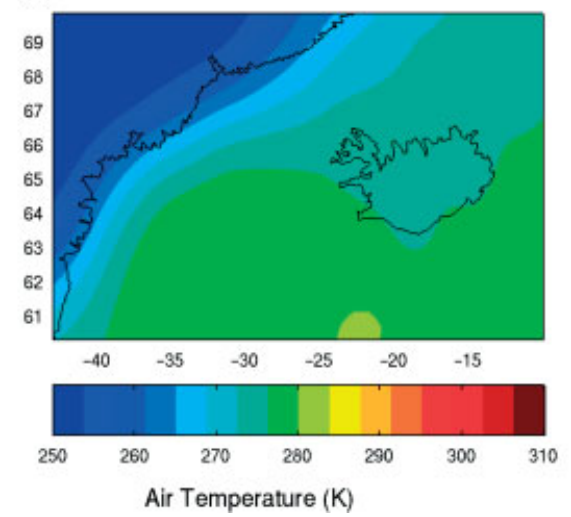

(c)

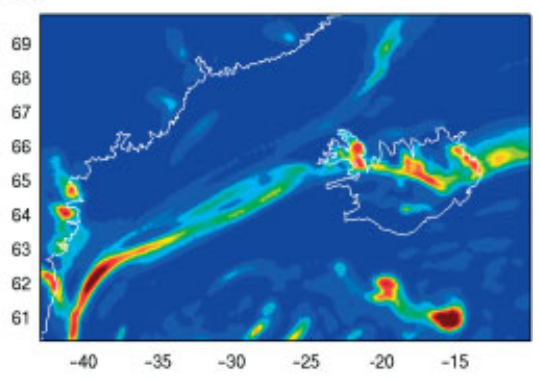

(f)

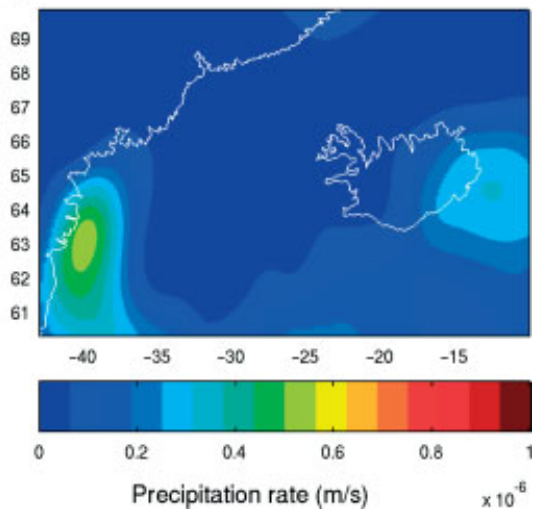

Figure 2. Forcing fields for the ocean circulation model at 0300 UTC on 9 March 2007. (a,b,c) show MM5 data (Expt. 1) and (d,e,f) NCEP data (Expt. 3). (a, d) show $10 \mathrm{~m}$ wind speed $\left(\mathrm{m} \mathrm{s}^{-1}\right),(b, e)$ surface air temperature $(\mathrm{K})$, and $(\mathrm{c}, \mathrm{f})$ surface precipitation rate $\left(\mathrm{m} \mathrm{s}^{-1}\right)$.

Table III. Mean results of numerical experiments.

\begin{tabular}{|c|c|c|c|}
\hline Diagnostic & Expt. 1 & Expt. 2 & Expt. 3 \\
\hline \multicolumn{4}{|l|}{ Dynamic variables } \\
\hline Peak zonal current $\left(\mathrm{m} \mathrm{s}^{-1}\right)$ & 1.9 & 1.7 & 1.6 \\
\hline Peak meridional current $\left(\mathrm{m} \mathrm{s}^{-1}\right)$ & 2.0 & 1.5 & 1.5 \\
\hline Peak vertical current $\left(\mathrm{m} \mathrm{s}^{-1}\right)$ & 0.051 & 0.054 & 0.061 \\
\hline Peak kinetic energy $\left(\mathrm{J} \mathrm{kg}^{-1}\right)$ & 2.4 & 1.9 & 1.8 \\
\hline Mean kinetic energy $\left(10^{-3} \mathrm{~J} \mathrm{~kg}^{-1}\right)$ & 6.0 & 5.3 & 5.3 \\
\hline Mean barotropic potential energy ${ }^{a}\left(10^{-6} \mathrm{~J} \mathrm{~kg}^{-1}\right)$ & 40 & 35 & 35 \\
\hline Sea-level range $(\mathrm{m})$ & -0.40 to 0.52 & -0.33 to 0.33 & -0.32 to 0.32 \\
\hline Relative vorticity range $\left(10^{-3} \mathrm{~s}^{-1}\right)$ & -1.8 to 1.7 & -1.2 to 1.5 & -1.4 to 1.5 \\
\hline \multicolumn{4}{|l|}{ Thermodynamic variables } \\
\hline Mean potential temperature $\left({ }^{\circ} \mathrm{C}\right)$ & 3.56 & 3.56 & 3.56 \\
\hline Potential temperature range $\left({ }^{\circ} \mathrm{C}\right)$ & -2.63 to 9.88 & -2.43 to 9.75 & -2.41 to 9.87 \\
\hline Mean salinity & 34.93 & 34.93 & 34.93 \\
\hline Salinity range & 30.84 to 35.25 & 30.58 to 35.25 & 30.63 to 35.41 \\
\hline
\end{tabular}

${ }^{a}=\left[\rho_{0} g /(2 M)\right] \int_{A} \eta^{2} \mathrm{dA}$, where $\rho_{0}$ is the reference density, $g$ is gravitational acceleration, $M$ is ocean mass, $A$ is surface area, and $\eta$ is the sea-surface height anomaly.

similar in both datasets, although the lower resolution in the NCEP field has smoothed out the cold tongue of air moving along the core of the barrier wind off east Greenland. The NCEP surface air temperature is also significantly lower than in MM5. The precipitation fields are significantly different: the MM5 data used in Expt. 1 exhibit a pattern with much more fine-scale structure and intense rainfall, mainly along the cold front to the southeast of the barrier wind. The MM5 data show a mean precipitation rate that is only $29 \%$ larger than the
NCEP data, but the peak rate is nearly three times larger at this time.

Figure 3 shows the net air/sea heat flux in each experiment, corresponding to the atmospheric forcing fields in Figure 2. The large-scale features in these fields are similar, as are the typical magnitudes. The barrier wind jet over the east Greenland shelf is responsible for substantial ocean heat loss, with the greatest fluxes at the edge of the sea ice (seen as thin stripes in Figure 3). The barrier wind heat loss in Expt. 1 (MM5 forcing) 

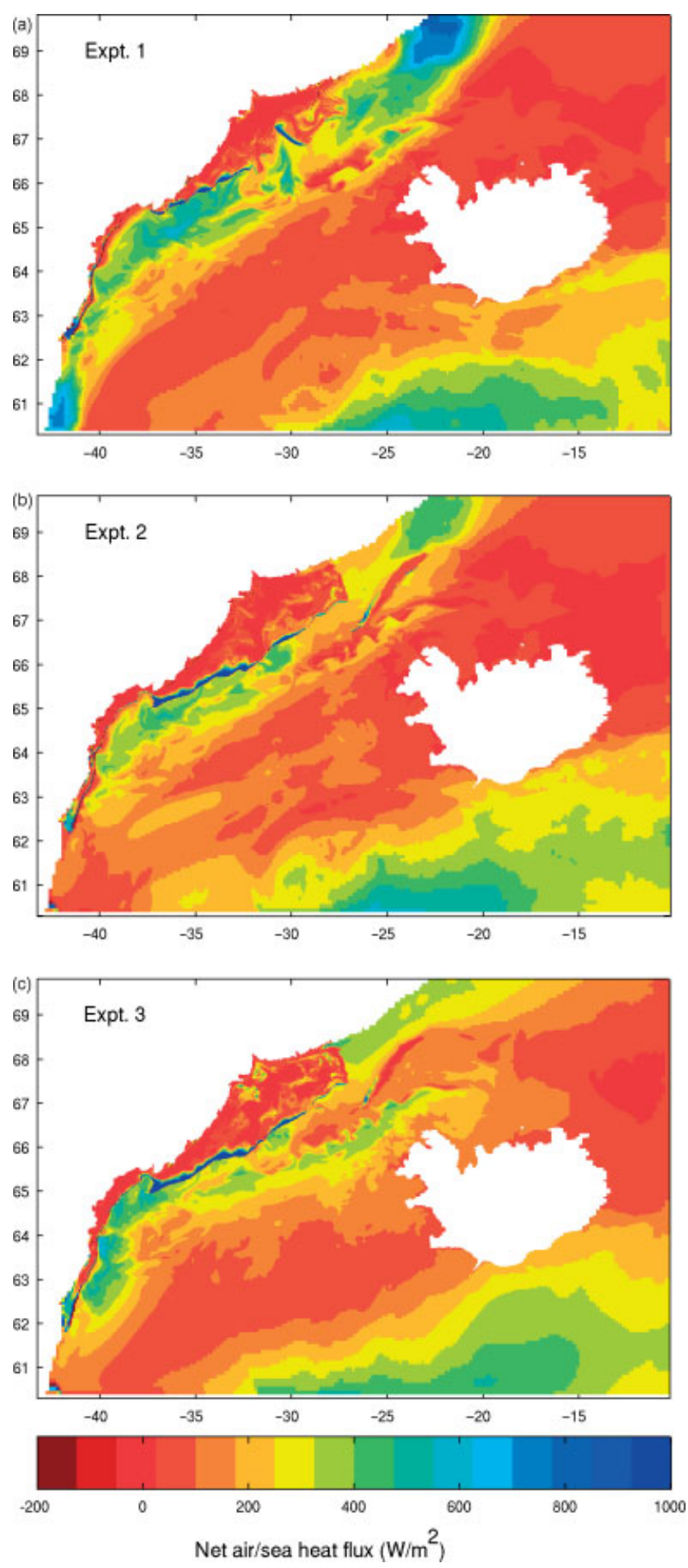

Figure 3. Net air/sea heat fluxes $\left(\mathrm{W} \mathrm{m}^{-2}\right.$; positive upwards) at 0300 UTC on 9 March 2007 corresponding to the atmospheric forcing fields shown in Figure 2.

exceeds that in Expts. 2 and 3 (NCEP wind forcing), due to the greater MM5 wind speed (Figure 2(a)). Expt. 3 has somewhat higher heat loss than Expt. 2, because Expt. 3 uses the colder, dryer NCEP data than the MM5 data (Figures 2(b), (e)). In this sense, the too-weak NCEP winds with too-cold air cause biases that compensate in the net air/sea heat flux. Although the NCEP barrier wind is too broad (Figure 2(d)), the region of high heat loss in
Expt. 3 is similar to that in Expt. 1 because the cold air is confined to the coast in the NCEP data (Figure 2(e)).

Table IV summarises some key diagnostics of the ocean circulation model from 9 March. The peak ocean current speed is $46 \%$ faster overall and $42 \%$ faster at the surface in Expt. 1 (forced with MM5 data). The mean speeds are 20-30\% faster. The energy is 30 and $61 \%$ greater (for kinetic and barotropic potential energy, respectively), and the sea-level range is $30 \%$ greater. For Expts. 2 and 3 these energy levels are only slightly greater than the average over the entire period of the experiment (cf. Tables III and IV). The Expt. 1 energy levels are significantly higher, however. There are negligible differences between the baroclinic available potential energies (which depends on the vertical distribution of the mass field) among the experiments on this day.

The frequency distributions (histograms) of surface ocean currents and sea surface height are significantly different (Figure 4). Figure 4(a) shows that current speeds have a long tail (possibly exponential) in all three experiments, but the slope is about $30 \%$ shallower for Expt. 1 forced with MM5 data. Sea-surface height also shows fatter tails and is more skewed to positive values (Figure 4(b)). All these differences are attributable to the stronger, more structured wind forcing in Expt. 1 than in Expt. 3 because Expt. 2 is negligibly different from Expt. 3.

Figure 4 also shows observations of surface currents and sea level for comparison with the model results. Seasurface current data from the OSCAR product (Bonjean and Lagerloef, 2002) are shown on Figure 4(a). These data are derived from altimetry, scatterometry, and seasurface temperature data (in situ and remotely sensed). They are provided in $5 \mathrm{~d}$ averages on a $1^{\circ}$ resolution grid (the data on Figure 4 are for the $5 \mathrm{~d}$ period centred on 7 March 2007). Compared to the model results, the OSCAR data show a similar peak in surface current distribution, and a similar tail to low speeds. They are too coarsely sampled to resolve the tail to high current speeds, however (the quantisation noise in the OSCAR distribution is visible, for instance). For this reason, they are not very helpful in evaluating the ocean model, although there is no sign of inconsistency. The altimetric sea-surface heights from AVISO are also shown on Figure 4(b) for 9 March 2007. Expt. 1 matches the altimetry observations reasonably well, including two peaks at about $-0.05 \mathrm{~m}$ and $0.18 \mathrm{~m}$. The model variability is less than the satellite data, however, particularly for sea levels below $-0.20 \mathrm{~m}$. The agreement is better with the envelope of AVISO sea-surface heights over the GFDEx period (dashed lines), but differences remain. The source of this bias is unclear; it could be due to too-weak atmospheric forcing, even in Expt. 1, or it could be because of the sponge layer boundary conditions which damp the model circulation, particularly at low sea levels in the southern Irminger Sea. In any case, the overall agreement with data, given these caveats, is reasonably good.

The frequency distributions of vertical relative vorticity and horizontal flow divergence also differ between the 
Table IV. Barrier wind: Results of numerical experiments at 1500 UTC on 9 March 2007.

\begin{tabular}{|c|c|c|c|}
\hline Diagnostic & Expt. 1 & Expt. 2 & Expt. 3 \\
\hline Peak current $\left(\mathrm{m} \mathrm{s}^{-1}\right)$ & 1.9 & 1.3 & 1.3 \\
\hline Mean current $\left(\mathrm{m} \mathrm{s}^{-1}\right)$ & 0.042 & 0.035 & 0.035 \\
\hline Peak surface current $\left(\mathrm{m} \mathrm{s}^{-1}\right)$ & 1.7 & 1.2 & 1.2 \\
\hline Mean surface current $\left(\mathrm{m} \mathrm{s}^{-1}\right)$ & 0.16 & 0.12 & 0.12 \\
\hline Kinetic energy $\left(10^{-3} \mathrm{~J} \mathrm{~kg}^{-1}\right)$ & 7.5 & 5.8 & 5.8 \\
\hline Barotropic potential energy $\left(10^{-6} \mathrm{~J} \mathrm{~kg}^{-1}\right)$ & 58 & 36 & 37 \\
\hline Baroclinic potential energy ${ }^{a}\left(\mathrm{~J} \mathrm{~kg}^{-1}\right)$ & 0.532 & 0.532 & 0.533 \\
\hline Sea-level range $(\mathrm{m})$ & -0.26 to 0.34 & -0.23 to 0.24 & -0.23 to 0.23 \\
\hline
\end{tabular}

$\bar{a}=(g / M) \int_{A} \int_{-H}^{0}(\rho-\bar{\rho}) z \mathrm{dzdA}$, where $H$ is the ocean depth and other variables are defined in Table III. $\bar{\rho}(z)$ is the density distribution that minimises potential energy via an adiabatic rearrangement of $\rho$.
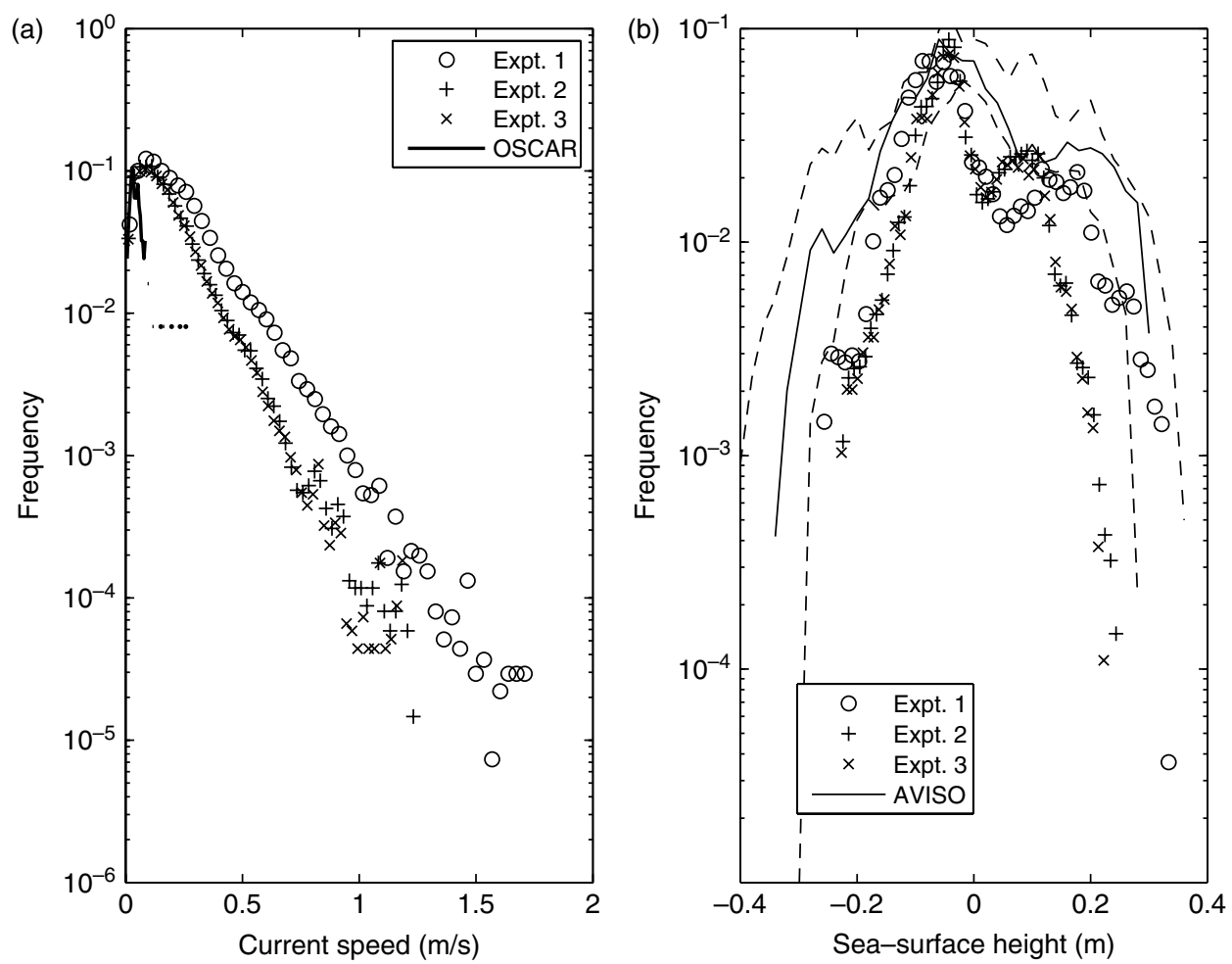

Figure 4. Distribution of (a) ocean surface current speeds $\left(\mathrm{m} \mathrm{s}^{-1}\right.$ ) and (b) sea-surface heights (m) at 1500 UTC on 9 March 2007 for each experiment. OSCAR surface current data are shown in (a) for the 5-day period centred on 7 March 2007 (bold solid line). AVISO sea-surface height data are shown in (b) for 9 March 2007 (solid line), and the envelope of AVISO heights over the GFDEx period is shown by dashed lines.

experiments, as shown in Figure 5. Expt. 1, forced with MM5 data, has fatter vorticity tails than Expts. 2 and 3 which differ insignificantly. The presence of fatter tails is most evident at extremely low and high relative vorticities; Expt. 1 has significantly more fluid with negative absolute vorticity, for example, indicated by the data points to the left of the vertical line in Figure 5. The asymmetry in the relative vorticity distribution (with cyclonic bias) is interesting, and present at other times, but it does not depend on the atmospheric forcing data used in these experiments (they all show this feature). The asymmetry is seen in mixed-layer current data too (Rudnick, 2001), and is due to $\mathrm{O}(1) \mathrm{km}$-scale vortices that are not directly related to the ambient gyre-scale cyclonic circulation (which involves much weaker vorticities). The differences in horizontal divergence are smaller than for vorticity, but Expt. 1 has significantly greater divergence than Expts. 2 and 3. Because Expts. 2 and 3 are indistinguishable in their diagnostics, these differences are attributable to the more energetic wind field in Expt. 1.

The surface ocean boundary-layer thicknesses are different between the different model experiments. Figure 6 shows that the boundary layer (as diagnosed from the Large et al., 1994, parametrisation) is substantially deeper in Expt. 3 using NCEP forcing than in Expt. 1. For example, there is a large patch southwest of Denmark Strait where the layer depth exceeds $500 \mathrm{~m}$. In Expts. 1 and 2 the thickness is $100-200 \mathrm{~m}$ in this region, and coherent bands of shallow boundary-layer thickness cut across the deep layer. Inspection of the forcing fields (Figure 2) 
(a)

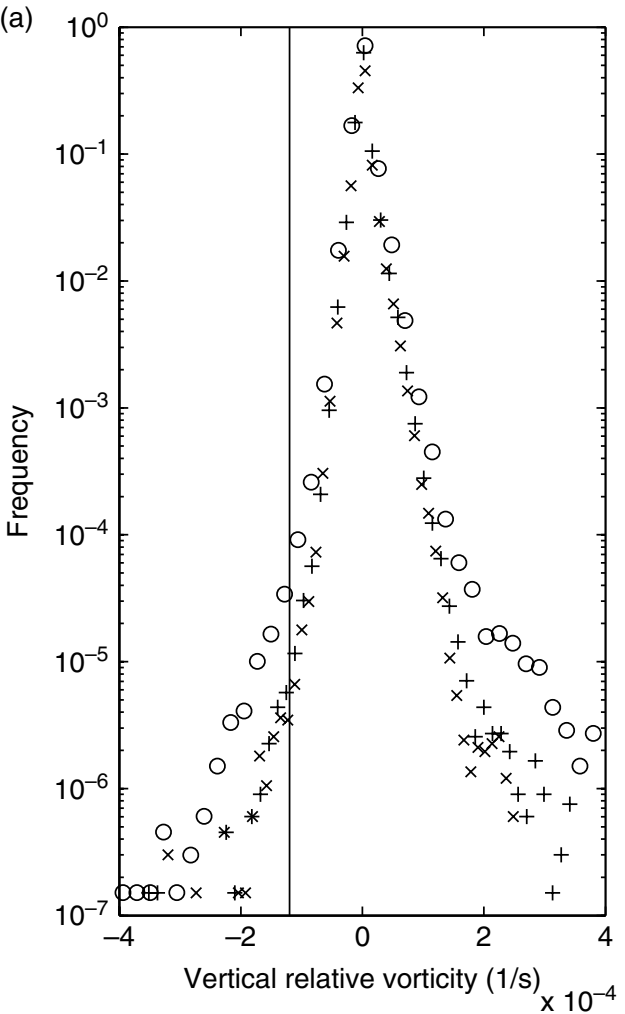

(b)

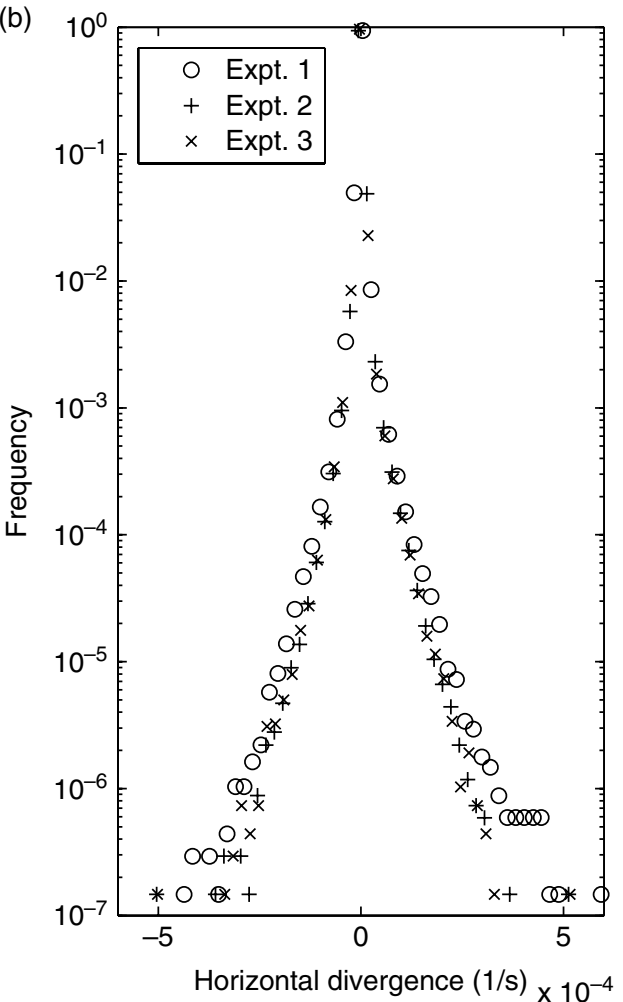

Figure 5. Distribution of surface-ocean (a) vertical relative vorticity $\left(\mathrm{s}^{-1}\right)$ and (b) divergence $\left(\mathrm{s}^{-1}\right)$ at 1500 UTC on 9 March 2007 for each experiment. The vertical line in (a) shows (minus) the maximum planetary vorticity in the model domain; fluid with vorticity less than this value is inertially unstable and overturns with a time-scale of order the inertial period - about $14 \mathrm{~h}$ at these latitudes (Haine and Marshall, 1998).

at this time shows the reasons for these differences. In particular, the shape of the barrier wind jet speed (Figures 2(a), (d)) and the associated rain band (Figures 2(c), (f)) matches the southwest-to-northeast trending stripes in the boundary-layer thicknesses (Figure 6). In Expt. 1 the jet is narrow and intense, and the peak in precipitation rate is also very narrow, elongated, and intense (consistent with observations; Renfrew et al., 2008). At the jet centre off Greenland, the mixed layer is deepest, but to the southeast flank the jet speed rapidly decreases and the precipitation rate rapidly increases. The turbulent kinetic energy source to the boundary layer therefore drops sharply and reinforces the stratifying effect of the rain to sharply decrease the boundary-layer thickness. In Expt. 3 the precipitation rate is much weaker and less focused, and the barrier wind is also much more diffuse. Here, the ocean responds by forming a boundary layer that is shallow under the broad minimum in wind speed to the southwest of Iceland, and deep to the northwest of this front. In Expt. 2, which is forced with the NCEP wind and the MM5 precipitation rate (Table I), we see evidence of both these effects: there is a broad stripe of shallow boundary layers associated with the minimum in wind speed from the NCEP forcing (as in Expt. 3), and there is a narrow band of shallow boundary layers from the rain bands in the MM5 forcing (as in Expt. 1).

The instantaneous boundary-layer depth is sensitive to the instantaneous air/sea forcing, as well as the accumulated flux history. As seen in Figure 6, the MM5 data forces narrow $(10-20 \mathrm{~km}$ wide) coherent fronts in boundary-layer thickness that are associated with the barrier wind shoulder and associated intense rain bands. Snapshots of the boundary-layer thickness fields at other times show similar features, although the locations and orientations of the boundary-layer fronts vary because the atmospheric fronts typically pass over the domain in just a few hours. Expt. 3 does not show narrow bands of shallow boundary-layer depth, however. The mean boundarylayer thicknesses are similar among the experiments, but vary on short periods. For example, at 0300 UTC on 9 March 2007 (the time of Figure 6) the values are 118, 105, and $128 \mathrm{~m}$ for Expts. 1-3, respectively, while $12 \mathrm{~h}$ later the values are 101, 69, and $60 \mathrm{~m}$. These average results reinforce the idea that the boundary layer responds rapidly and sensitively to the local atmospheric conditions.

In contrast, the hydrographic composition of the upper ocean represents the accumulated effects of the diabatic air/sea forcing, and the cycling of water through the boundary layer. In these diagnostics the differences between the three experiments are much more muted. For instance, the sea-surface salinity fields do not show significant differences at 0300 UTC on 9 March 2007 associated with the different boundary-layer thicknesses in Figure 6 (not shown). The organised suppression of deep mixing due to the intense rain in Expt. 1 is not evident in the salinity field, because the salinity signals from mesoscale activity, and the primary front between warm, salty Irminger water and cold, fresh East Greenland shelf water, are much larger. Moreover, the temperature/salinity diagrams for the three experiments 

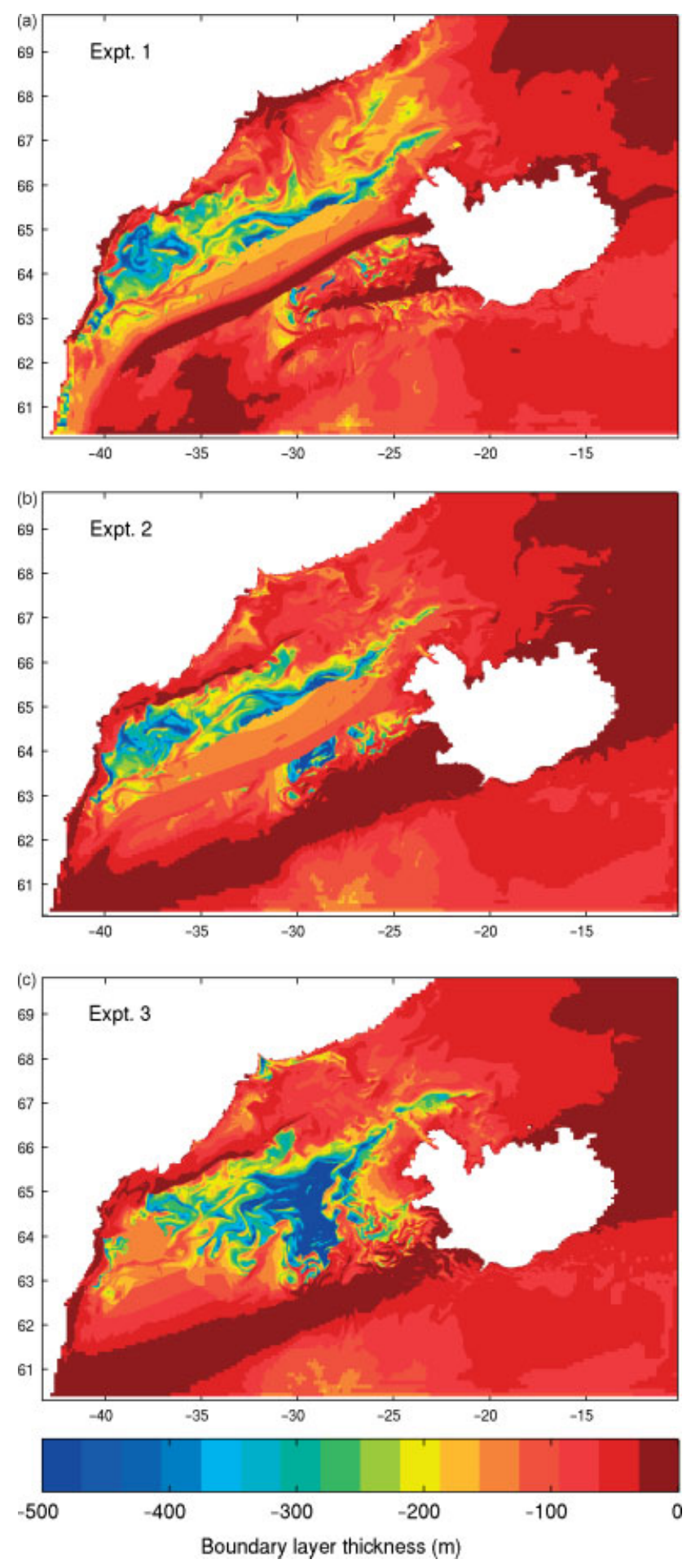

Figure 6. Oceanic boundary-layer thickness (m) at 0300 UTC on 9 March 2007: (a) Expt. 1, (b) Expt. 2, and (c) Expt 3.

show significant but relatively minor differences, as seen in Figure 7. This diagram is for the final day of the experiment when the largest differences in water composition are evident. The mean temperatures and salinities for Expts. 1-3 over the upper $819 \mathrm{~m}$ are (3.18 $\left.{ }^{\circ} \mathrm{C}, 34.74\right),\left(3.12^{\circ} \mathrm{C}, 34.70\right)$, and $\left(3.09^{\circ} \mathrm{C}, 34.70\right)$, respectively. Again, the differences in these average properties are small between the experiments. Looking at the distribution of water properties in Figure 7 in (a)

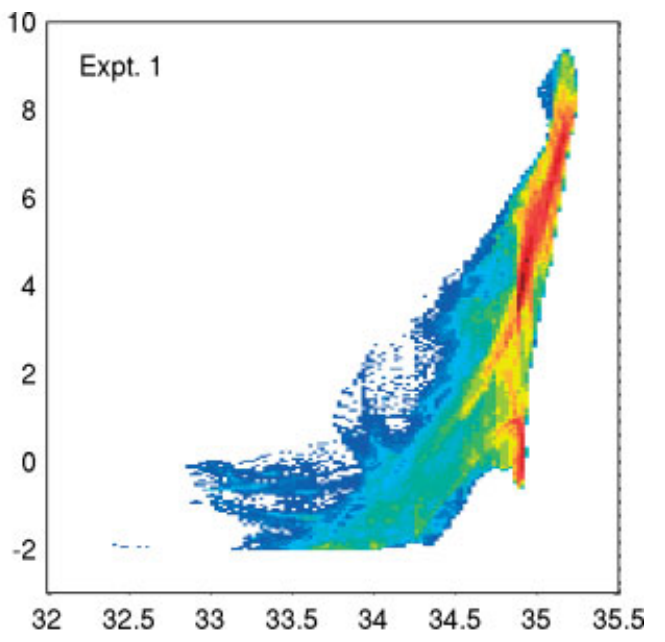

(b) 10
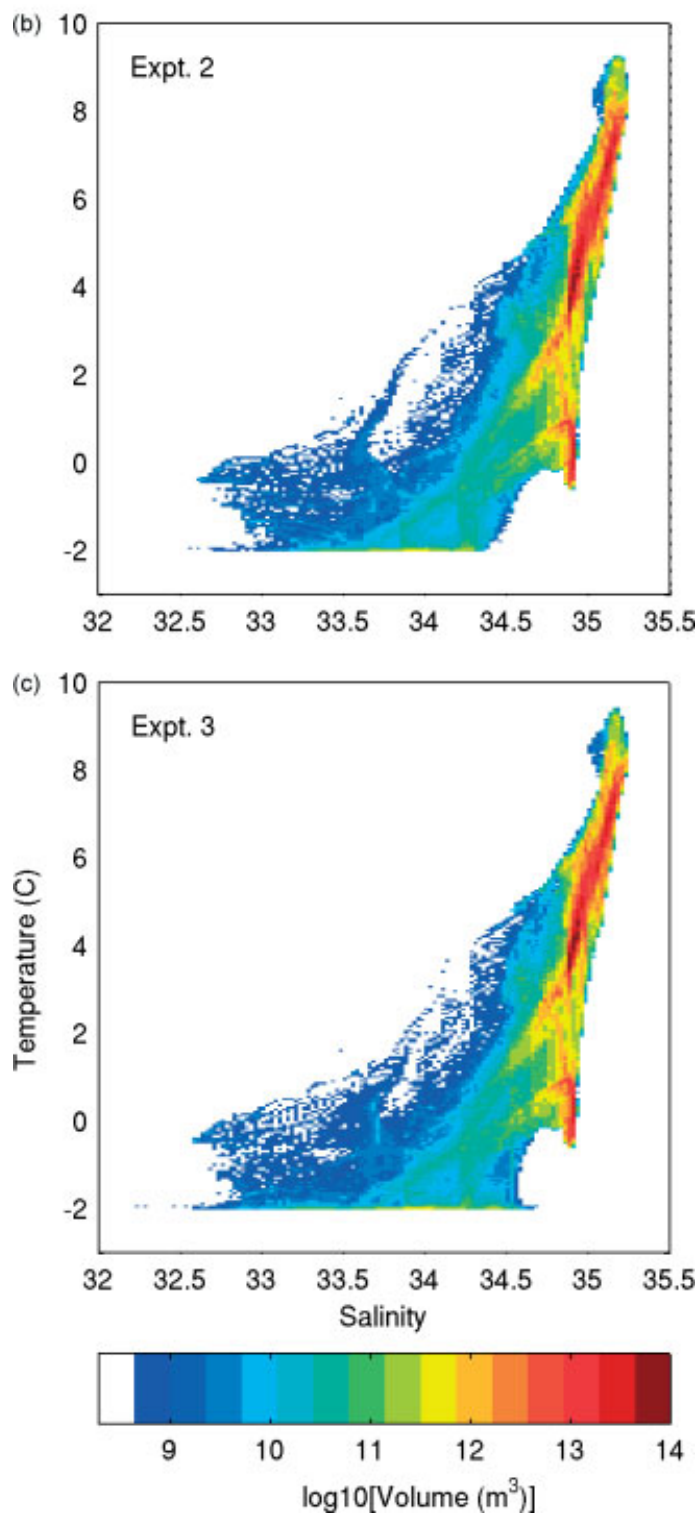

Figure 7. Temperature/salinity histograms for 0300 UTC on 14 March 2007 for the upper $819 \mathrm{~m}$ in (a) Expt. 1, (b) Expt. 2, and (c) Expt 3.

detail, we see that Expt. 3 (NCEP forcing) has more shelf water at salinities less than about 34 than Expt. 1, and Expt. 2 is intermediate. Expt. 3 also has more water at 
the freezing point for all salinities (the freezing line is seen in Figure 7 as the nearly horizontal lower bound to the water classes near $-2{ }^{\circ} \mathrm{C}$ ). In contrast, Expt. 1 has greater volumes of water along the broad line joining (roughly) $\left(-2{ }^{\circ} \mathrm{C}, 33.75\right)$ and $\left(2^{\circ} \mathrm{C}, 35\right)$; in this experiment the water mass classes are more tightly confined in temperature-salinity space. These findings are consistent with the similar time-averaged thermodynamic results in Table III and the similar baroclinic potential energies in Table I. They are not particularly surprising, given the short duration of the experiments, and the fact that the net air/sea heat and freshwater fluxes are similar (Table II). A longer period is needed for the contrasts in air/sea forcing fluxes to accumulate. In other words, the hydrographic composition of the ocean is relatively insensitive over a few weeks to the high-frequency, high-resolution atmospheric state, unlike the boundarylayer thickness which reflects the instantaneous mixing intensity.

\subsection{Polar low case}

Another interesting case-study during the GFDEx campaign occurred on 25 February 2007 when a mesoscale cyclone was present northeast of Iceland (centred at about $8^{\circ} \mathrm{W}, 69^{\circ} \mathrm{N}$; Renfrew et al., 2008). Peak winds in this polar low were near $25 \mathrm{~m} \mathrm{~s}^{-1}$, based on dropsondes along a flight leg at $68^{\circ} \mathrm{N}$; surface winds were between 5 and $20 \mathrm{~m} \mathrm{~s}^{-1}$, increasing towards the cyclone centre. The flow west of the cyclone (north of Iceland) was northerly. As for the barrier wind case, the NCEP data lack fine-scale structure associated with this northerly flow, although the magnitudes of the two surface wind products are similar. The MM5 data show flow separation near Liverpool Land (on the northern side of Scoresbysund at $70.5^{\circ} \mathrm{N}$ ) and weak winds in the lee of Greenland to the southwest. This weak flow over the southeast Greenland shelf is missing in the NCEP data which overestimates the wind speed, and has inadequate resolution to capture orographic steering of this type (not shown).

Table V shows values of key fields from the polar low case. Expt. 1 (MM5 forcing) shows greater peak and mean current speeds than Expts. 2 and 3, which are nearly identical. This finding holds for surface speed too, although the differences are smaller. The peak current speed exceeds the surface current speed, as seen for the barrier wind in Table IV (the fastest flow occurs in a deep jet attached to the east Greenland continental slope at around $730 \mathrm{~m}$ depth). Consistent with the higher currents in Expt. 1, the kinetic energy is also higher with MM5 wind forcing. The potential energies and the sealevel ranges are indistinguishable for this case, however. Compared to the results for the whole experimental period (Table II), the circulation during the polar low is weaker than the time-mean value. The histograms of surface current speed, vertical relative vorticity, and divergence all show greater variance in Expt. 1, but the differences (and the absolute values) are smaller than for the barrier wind case (not shown). There are negligible differences in boundary-layer thickness between the experiments at 0300 UTC on 25 February 2007.

The impact of the high-resolution, high-frequency MM5 forcing fields for the polar low event are much less obvious than for the barrier wind event. Several reasons are likely responsible: First, the polar low occurred earlier in the experimental period than the barrier wind studied in section 3.2 ( $12 \mathrm{~d}$ from the start, compared to $24 \mathrm{~d}$ ). Therefore, there is less time for the forcing differences to accumulate in the polar low case. Second, the polar low persisted for only about $2 \mathrm{~d}$, whereas the barrier wind was present for about $5 \mathrm{~d}$. Again, there was less opportunity for the MM5 fields to drive differences from the NCEP-forced experiments. Finally, the polar low was centred at the northeast corner of the ocean model domain. Most of the feature was outside the model domain, and the northerly airflow to the southwest of the central depression is partly in the ocean model sponge layer where the ocean model resolution is coarsest. Some of the muted differences in response to the polar low are therefore attributable to the way the ocean model experiments are configured. Nevertheless, it is reasonably clear that the ocean circulation near Denmark Strait was not significantly impacted by the small-scale structure of this particular polar low.

\subsection{Impact on sea ice}

In Figure 8 we show time series of the sea ice volume, area, and the average sea ice thickness for each experiment. The start and end times of the 12 GFDEx flights are shown as pairs of vertical lines on the diagram. In nature, most sea ice off southeast Greenland is advected into the region from the north, with very little sea ice found in deep water. This flux of remotely formed ice is missing from our numerical model because of the closed northern wall at $70^{\circ} \mathrm{N}$. The ice formed in the numerical model therefore forms locally within the model domain within one winter. As remotely formed ice is excluded by construction, the model underestimates the true ice coverage and thickness. Nevertheless, the period of the numerical experiments is mainly a time of melting, and the differences between the three runs are still revealing. The sea ice shows sensitive dependence to the atmospheric forcing fields, and to their differences. The ice also responds to wind speed, air temperature, and humidity in subtle ways.

All three experiments show progressive decrease in ice volume and area during the month-long integrations, with little day-to-day variability. A substantial fraction of the initial ice is lost overall, with Expt. 2 showing the greatest melt (85\% volume lost) and Expt. 3 the least (46\% lost). All three experiments exhibit an increase in sea ice volume and area for about one week in late February and early March, however. The cause of this ice volume increase is an outbreak of frigid air from the Arctic (Petersen et al., 2009). Although the northeasterly jet through the Denmark Strait is weaker on 2 March 2007 than during the barrier wind event one week later, the air temperature is colder - and hence dryer - by 
Table V. Polar low: Results of numerical experiments at 1500 UTC on 25 February 2007.

\begin{tabular}{llll}
\hline Diagnostic & Expt. 1 & Expt. 2 & Expt. 3 \\
\hline Peak current $\left(\mathrm{m} \mathrm{s}^{-1}\right)$ & 1.4 & 0.99 & 0.98 \\
Mean current $\left(\mathrm{m} \mathrm{s}^{-1}\right)$ & 0.032 & 0.030 & 0.030 \\
Peak surface current $\left(\mathrm{m} \mathrm{s}^{-1}\right)$ & 0.73 & 0.70 & 0.70 \\
Mean surface current $\left(\mathrm{m} \mathrm{s}^{-1}\right)$ & 0.085 & 0.081 & 0.080 \\
Kinetic energy $\left(10^{-3} \mathrm{~J} \mathrm{~kg}^{-1}\right)$ & 4.9 & 4.7 & 4.7 \\
Barotropic potential energy $\left(10^{-6} \mathrm{~J} \mathrm{~kg}^{-1}\right)$ & 33 & 32 & 32 \\
Baroclinic potential energy $\left(\mathrm{J} \mathrm{kg}^{-1}\right)$ & 0.531 & 0.531 & 0.532 \\
Sea-level range $(\mathrm{m})$ & -0.30 to 0.20 & -0.29 to 0.21 & -0.29 to 0.21 \\
\hline
\end{tabular}

$10-15 \mathrm{~K}$. Inspection of synoptic sea-level pressure maps shows that isobars (and thus the geostrophic wind) run parallel to the entire length of the Greenland coast from 28 February to 2 March 2007. Polar air was passing through Fram Strait to reach the Denmark Strait and southeast Greenland at that time. During the barrier wind on 9 March, the air originated from the Norwegian Sea and was therefore significantly warmer. This synopticscale cold-air outbreak is captured by both MM5 and NCEP.

The sea ice differences between the experiments are also interesting. First, consider Expts. 2 and 3, both forced by NCEP winds, because this pair isolates the effect of sea ice thermodynamics only. We see that Expt. 3 has greater ice volume, area, and thickness than Expt. 2 at all times. These differences are due to colder, dryer air over the east Greenland coast in the NCEP product than in the MM5 product, and therefore greater ocean heat loss in Expt. 3. The colder air can be seen at 0300 UTC on 9 March in Figure 2, for example, where NCEP is $10-15 \mathrm{~K}$ colder than the MM5 data (also Figure 3). Next, notice that the sea ice area is almost identical in Expts. 1 and 2, and both are less than in Expt. 3. In fact, the maps of sea ice concentration differ in Expts. 1 and 2: Expt. 1 shows higher concentrations closer to the coast, whereas the Expt. 2 sea ice field is more diffuse and spread further offshore (not shown). This difference is attributable to the stronger northeasterly MM5 wind in Expt. 1 which pushes the ice harder against the coast. The similarity of sea ice area for Expts. 1 and 2 is therefore coincidental. Finally, consider that the Expt. 1 ice volume lies between the other two experiments at all times. This curious fact is harder to explain because both sea ice dynamics and thermodynamics are in play. The stronger MM5 wind and the lower NCEP air temperature and humidity both favour greater ocean heat loss. Thus, in Expt. 1 we should expect greater heat loss, and ice volume, than in Expt. 2, because of the stronger MM5 wind. In Expt. 3 we should expect greater heat loss, and ice volume, than in Expt. 2, because of the colder, dryer NCEP air. Figure 8 confirms both these ideas, and shows that the impact of the cold dry NCEP air exceeds the impact of the stronger MM5 wind. Other factors are likely also important, however. The stronger MM5 wind also tends to compress the ice against the coast more, for example, where it is somewhat sheltered from the peak frigid wind (Figure 2), and heat loss occurs over a smaller area of more concentrated sea ice. Moreover, we see net ice melt during the experimental period despite consistent ocean heat loss. Clearly mixing of heat into the ice zone, both from offshore and below, dominates the sea ice heat budget overall, although the surface heat flux plays a vital role in the variations over the experimental period, and between experiments.

\subsection{Volume, heat, and freshwater fluxes}

Next we turn to examine the fluxes of key physical quantities in the ocean circulation experiments. Figure 9 shows time-varying fluxes of volume, heat, and freshwater across a $900 \mathrm{~km}$ segment of the Greenland shelf-break following the $550 \mathrm{~m}$ depth contour. The shelf-break section is shown in Figure 1(a), and the heat and freshwater fluxes are computed as anomalies relative to a temperature and salinity of $2{ }^{\circ} \mathrm{C}$ and 34.80 , respectively. (Note that although the physical meaning of the absolute magnitudes of the heat and freshwater fluxes is ambiguous, because they depend on these reference values, relative comparisons are revealing. To convert the flux numbers here to fluxes computed using different reference values, offset our numbers with the product of the difference in reference values and the appropriate volume flux.)

The volume transport time series show values fluctuating between $\pm 5 \mathrm{~Sv}$ ( $1 \mathrm{~Sv}$ is $10^{6} \mathrm{~m}^{3} \mathrm{~s}^{-1}$ ), corresponding to section-average onshore currents of $\pm 1 \mathrm{~cm} \mathrm{~s}^{-1}$. The time-mean values shown are $-0.52,-0.27$, and -0.48 for Expts. 1-3, respectively, indicating weak offshore flow on average. The differences in the shelf-break transport between the experiments are clearly associated with the wind. The evidence is that Expts. 2 and 3 are nearly identical for the entire period of the experiments, whereas Expt. 1, forced by the high-resolution wind product, diverges after a few days. In contrast, the small differences that exist between Expts. 2 and 3 take about $17 \mathrm{~d}$ to emerge on Figure 9. Athough the variations are similar, Expt. 1 (MM5 forcing) has greater volume flux variance (1.6 Sv compared to 1.4 Sv in Expt. 3).

The cross-shelf heat and freshwater fluxes show a similar picture. The heat flux exhibits variability of $17 \mathrm{TW}$ around a mean of $66 \mathrm{TW}$ for Expt. 1. Interestingly, the results from Expts. 2 and 3 are almost indistinguishable in Figure 9, and are closer to one another than the volume 
(a)

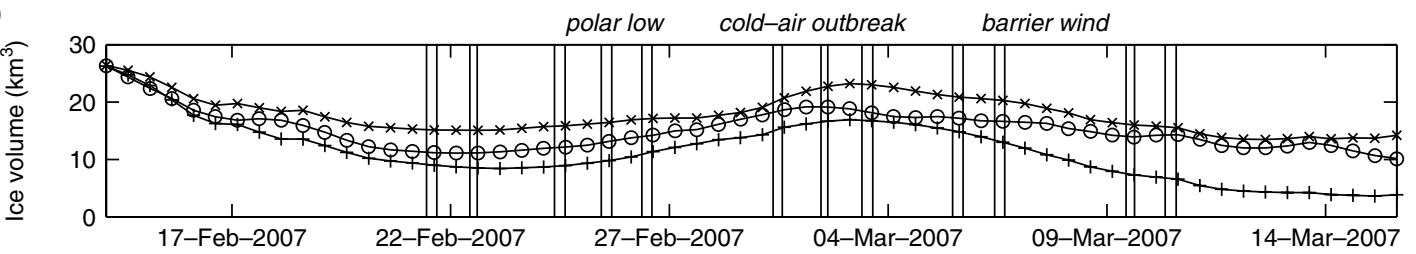

(b)
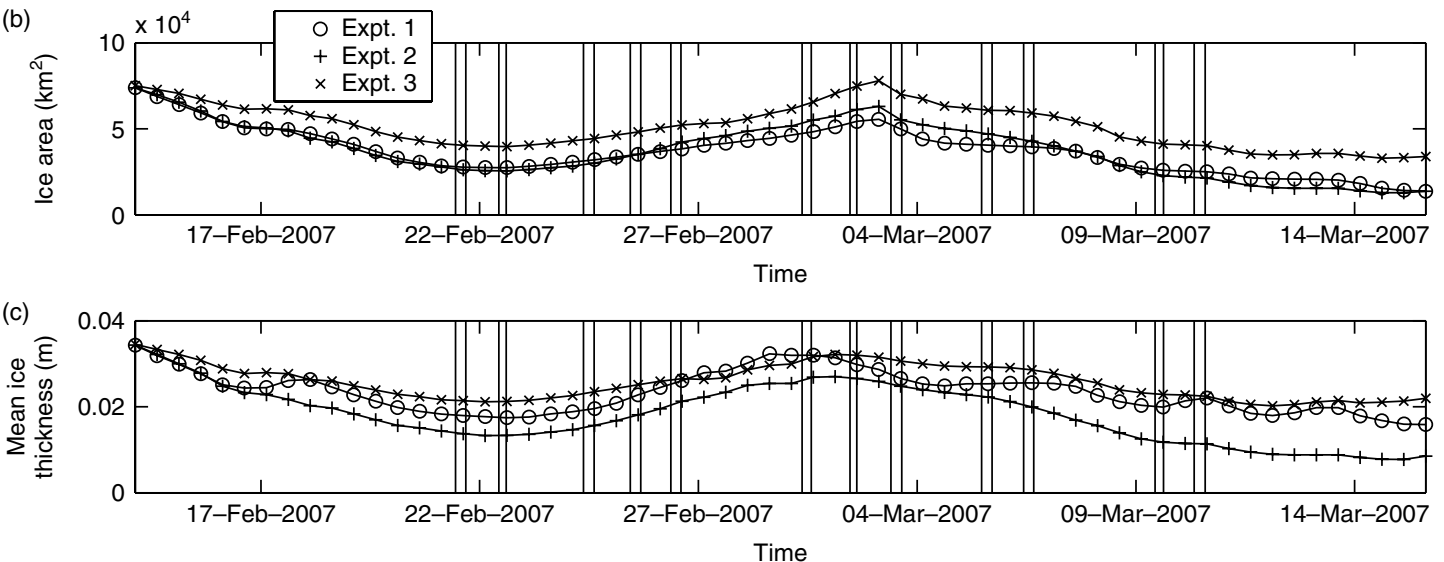

Figure 8. Time series of (a) total sea ice volume $\left(\mathrm{km}^{3}\right)$, (b) total sea ice area $\left(\mathrm{km}^{2}\right)$, and (c) mean sea ice thickness (m). All three experiments are shown, with pairs of lines indicating the times of the GFDEx flights. The times of the barrier wind, polar low, and cold-air outbreak discussed in sections 3.2, 3.3, and 3.4, respectively, are marked.

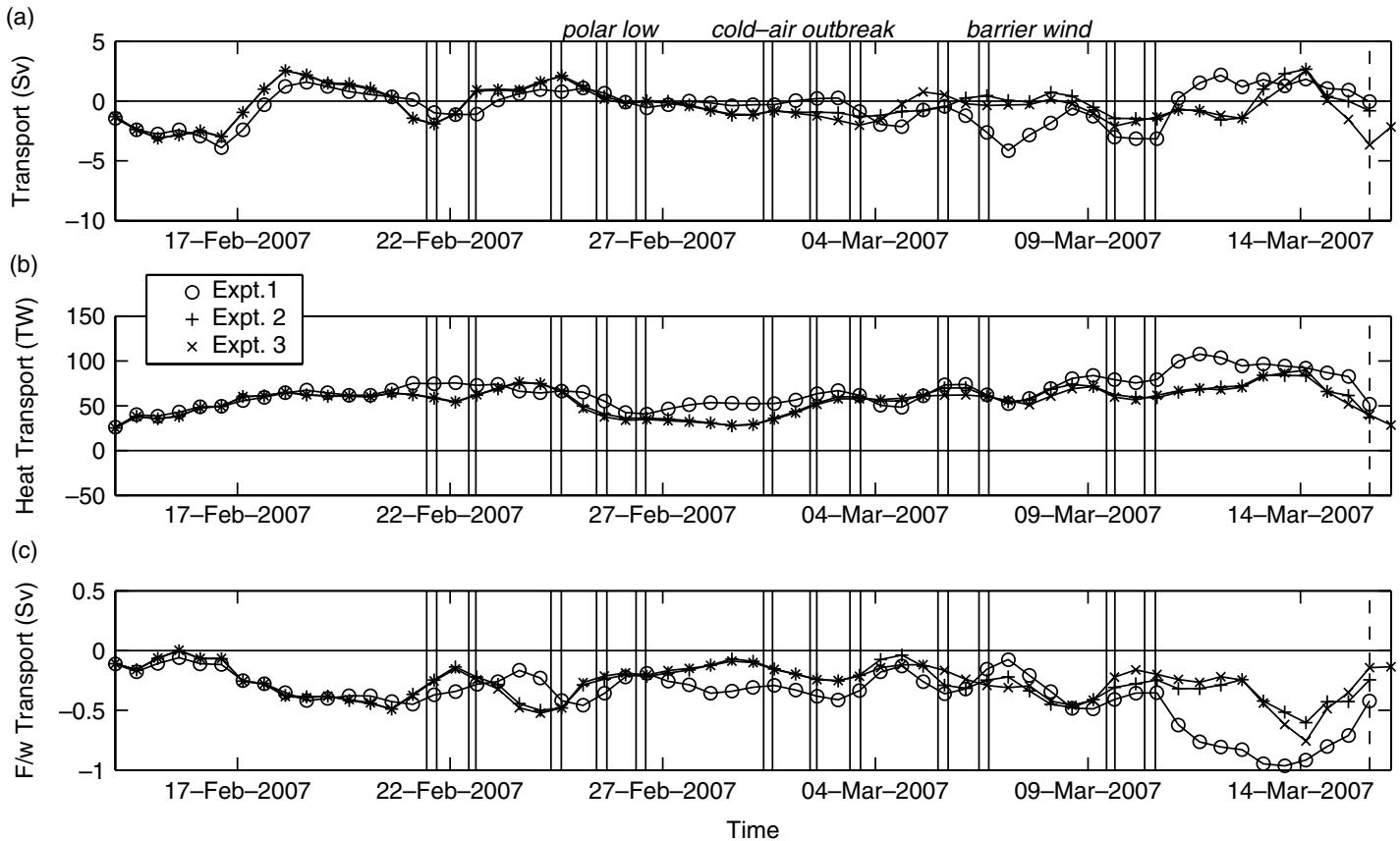

Figure 9. Time series of net shelf-break fluxes across the transect shown in Figure 1 which follows the $550 \mathrm{~m}$ depth contour for $900 \mathrm{~km}$, starting at the Denmark Strait. The dashed line shows the time of the cumulative fluxes shown in Figure 10; other details are as in Figure 8. (a) Volume flux transport $\left(\mathrm{Sv} ; 1 \mathrm{~Sv}=10^{6} \mathrm{~m}^{3} \mathrm{~s}^{-1}\right)$, (b) heat flux (TW; $1 \mathrm{TW}=10^{12} \mathrm{~W}$ ) relative to a reference temperature of $2{ }^{\circ} \mathrm{C}$, (c) freshwater flux $(\mathrm{Sv})$ relative to a reference salinity of 34.80 . Positive volume fluxes indicate onshore transport. The time series are filtered with a running mean over a period of $1 \mathrm{~d}$.

flux series. This result means that there is a compensation effect at work for the heat fluxes: changes in volume flux are correlated with changes in temperature so as to reduce the variations in heat flux. Nevertheless, the influence of temperature changes on heat flux variability is relatively weak, and heat flux changes are mainly driven by changes in the wind. Consistent with this idea, the correlations of volume and heat flux variability are 0.46 , 0.49 , and 0.48 for Expts. 1-3, respectively (all significant). For freshwater, the time-average flux for Expt. 1 is $-0.38 \pm 0.22 \mathrm{~Sv}$. Again, the wind accounts for the main differences between the experiments (cf. Expt. 1 with Expts. 2 and 3) and the correlation with the volume flux time series are $-0.68,-0.74$, and -0.68 (all highly 
significant). These results suggest that heat and freshwater flux variations are primarily driven by changes in volume flux, rather than changes in temperature or salinity.

Figure 10 shows how the shelf-break fluxes of Figure 9 vary with spatial position along the $900 \mathrm{~km}$ transect shown in Figure 1(a). On this diagram, $5 \mathrm{~Sv}$ over $100 \mathrm{~km}$ corresponds to an average current of $9 \mathrm{~cm} \mathrm{~s}^{-1}$. The results are shown for one particular day, 1500 UTC on 15 March 2007, at the end of the experimental period (shown on Figure 9 with the dashed line). At this time, the three experiments show significant differences within $150 \mathrm{~km}$ of the start of the transect, near the Denmark Strait. This region is where the Denmark Strait Overflow Water (DSOW) is spilling into the North Atlantic Ocean and variability in DSOW volume flux with periods of $2-4 \mathrm{~d}$ is known to exist (Bruce, 1995). This episodic overflow process is responsible for the differences seen in the first $150 \mathrm{~km}$ of the transect along the shelf-break (also see discussion below on Figure 12). In Expt. 3 at this time a strong surge of DSOW is moving south near the intersection of the two transects shown in Figure 1(a) (that is, southeast across the shelf-break section and southwest across the Denmark Strait section). Downstream of this location, the cross-shelf volume fluxes are well correlated between the three experiments. This result shows that the cross-shelf volume flux occurs at specific places along the shelf-break, independent of the forcing used. The anomalies at the cape near $550 \mathrm{~km}$ is a good example of this phenomenon. Interestingly, the location of the socalled East Greenland Spill Jet - a narrow, extremely intense, cascade identified by Pickart et al. (2005) near $65.5^{\circ} \mathrm{N}$, and shown in Figure 10 with a dashed line - is not associated with strong cross-shelf-break volume flux.
Nevertheless, the Spill Jet is mainly deeper than $550 \mathrm{~m}$, and is mainly along the depth contours, not across them.

The heat and freshwater fluxes seen in Figure 10 are consistent with the idea that current changes are the main controlling factor, not temperature or salinity variability. The heat fluxes are very similar among all three experiments and show a progressive increase in the cumulative flux downstream. As in Figure 9, there is a compensation between velocity and temperature perturbations that reduces the heat flux variability compared to the volume flux variability in all three experiments. Compared to the other experiments, the freshwater flux in Expt. 3 shows anomalous values near the Denmark Strait due to an overflow surge, like the volume flux. Expt. 1 shows a greater increase in offshore freshwater flux than Expt. 2 between 200 and $900 \mathrm{~km}$, however, unlike the volume flux. This feature associates with differences in the Expt. 1 salinity field compared to the other experiments. At other times, Expt. 2 freshwater fluxes look very similar to Expt. 3 freshwater fluxes (not shown), as seen in the total flux time series shown in Figure 9.

To further explore the connection between the shelfbreak variability and the wind field, we show in Figure 11 a long transport time series, and the associated crossshelf-break Ekman transport. The section in this case follows the $550 \mathrm{~m}$ isobath, as for Figure 9, but the first $200 \mathrm{~km}$ is now removed to avoid the Denmark Strait overflow variations (Figure 1). We also show only Expt. 3, because this NCEP-forced calculation is available from 1 June 2006 to 3 April 2007, unlike the other runs. The cross-shelf volume flux from Expt. 3 shows little change with season and is consistently negative (offshore). The period of numerical experiments, centred
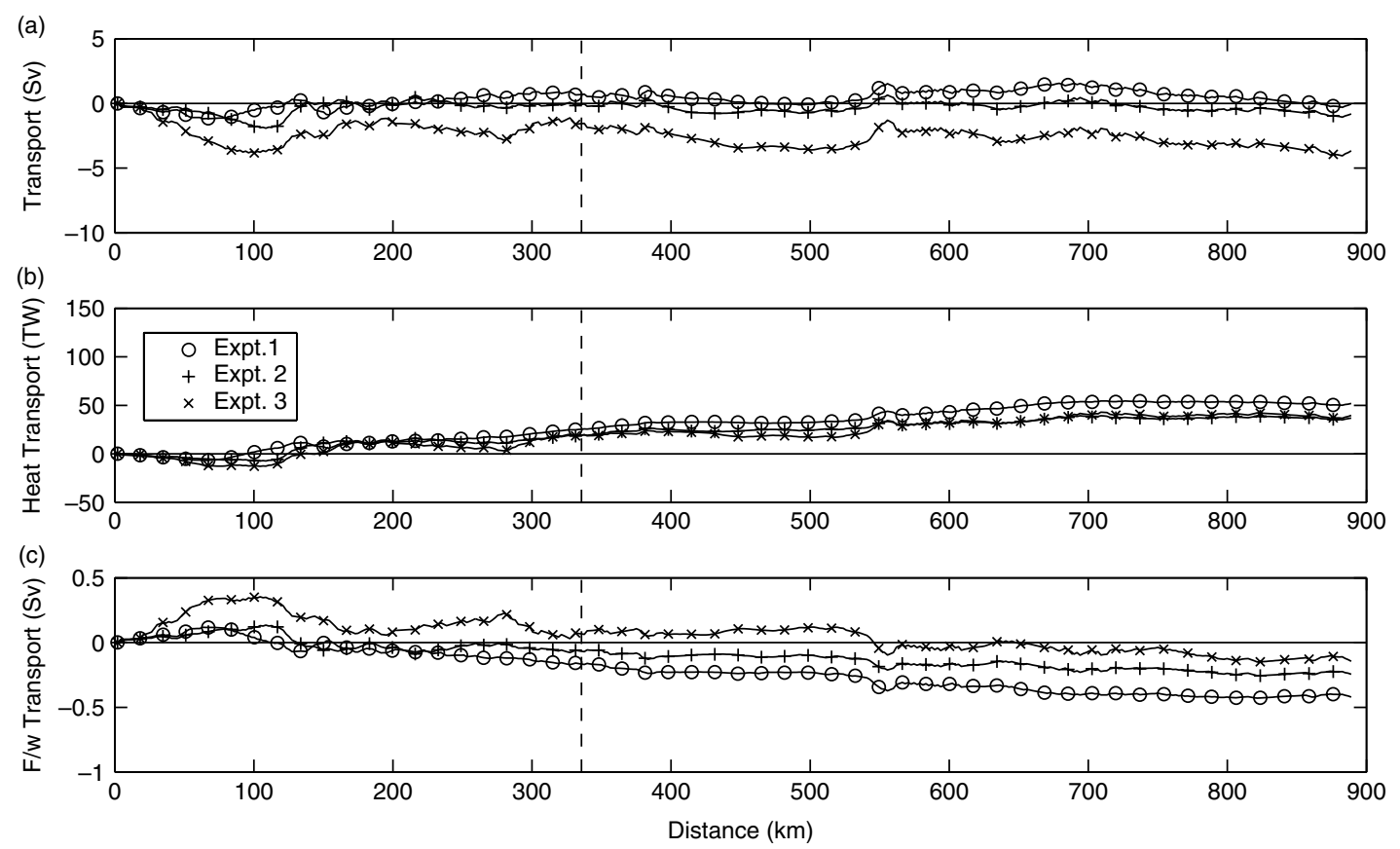

Figure 10. Cumulative shelf-break fluxes for 1500 UTC on 15 March 2007 across the transect shown in Figure 1. The data are filtered with a running mean over a length-scale of $6 \mathrm{~km}$. Distance along the transect is measured towards the southwest, starting from the Denmark Strait. The dashed line shows the location of the East Greenland Spill Jet (Pickart et al., 2005). Other details are as in Figure 9. 


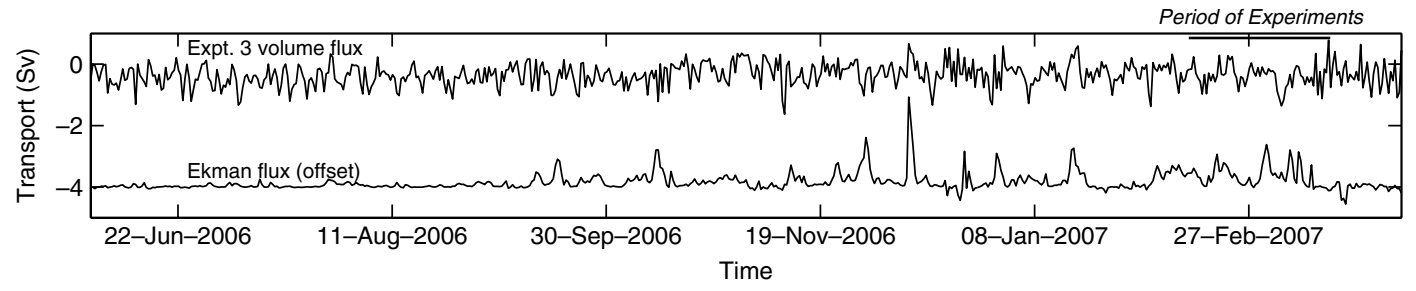

Figure 11. Time series of net shelf-break fluxes across the transect shown in Figure 1 which follows the $550 \mathrm{~m}$ depth contour for $700 \mathrm{~km}$, starting $200 \mathrm{~km}$ south of the Denmark Strait. Results from Expt. 3 are shown and the Ekman flux computed from the stress of the wind on the ocean (offset by $4 \mathrm{~Sv}$ ). Positive fluxes indicate onshore transport. The time series are filtered with a running mean over a period of $1 \mathrm{~d}$.

on the GFDEx campaign, is typical of the whole 10month record. The Ekman flux, computed from the model wind stress, is also shown. One might expect the Ekman transport to be correlated with the model volume flux, but this is not true. The Ekman flux shows significant seasonality, with greater variance in winter, as expected. It is also consistently positive (onshore; note the Ekman flux is offset on Figure 11), reflecting the prevailing northeasterly winds over the Denmark Strait and the northern Irminger Sea. Both of these facts contradict the volume flux from Expt. 3. Hence, there is no simple relation between the wind field and the shelf-break transport, even though the differences between Expts. 1-3 seen in Figure 9 are attributable to the wind forcing.

Finally, we show in Figure 12 time series of the fluxes leaving the Denmark Strait (Figure 1(a) shows the transect location). Unsurprisingly, the volume flux is always negative in each experiment, indicating consistent equatorward flow. Outflow variations on a time-scale of 3-4 d are clearly evident in each experiment, consistent with break-up of the incipient overflow into cyclonic boluses which are visible as cold core rings in seasurface temperature imagery (Bruce, 1995). Although the periodic formation of overflow boluses is clearly an intrinsic dynamical process in the ocean, the wind forcing is influential to some degree. This result is seen in the volume flux data in Figure 12 as the departure of Expt. 1 from Expts. 2 and 3 after a few days. The timing of the overflow perturbations is altered in Expt. 1, but not enough to completely disrupt the coherence of the three time series over the experimental period. The strong barrier wind event on 9 March 2007 is not accompanied by any unusual overflow anomalies.

Unlike the shelf-break fluxes, the Denmark Strait heat and freshwater fluxes do not show a strong correlation with the volume flux time series (for example, the heat and volume flux correlation coefficients are $0.26,0.18$, and 0.13 - none very significant - for Expts. 1, 2, and 3, respectively). The Expt. 2 and 3 results are very close to each other (compared to Expt. 1) however, which means that the wind forcing is responsible for the differences between the experiments. These two results imply that the MM5 wind field impacts the velocity, temperature, and salinity fields so as to perturb the Denmark Strait volume, heat, and freshwater fluxes. The other MM5 forcing fields have very little impact on these Denmark Strait fluxes, however.

\subsection{Impact of high-frequency forcing}

Next, we ask if the differences due to the high-resolution, high-frequency MM5 forcing, compared to the NCEP forcing, arise from the high spatial or temporal resolution in MM5. To address this question, we perform another experiment (Expt. 4). This calculation is identical to Expt. 1, except that the MM5 forcing is provided at 6hourly intervals, like the NCEP forcing, not hourly. We do not present full results for Expt. 4 because it is so similar to Expt. 1. For example, the peak currents at the time of the barrier wind discussed in section 3.2 (1500 UTC on 9 March) are just 1\% different, and the kinetic energy is just 1\% larger in Expt. 1 than in Expt. 4 (recall from Table IV that Expt. 3 has 30\% lower kinetic energy than Expt. 1). In the diagnostics shown on Figures 4 and 5, Expt. 4 is essentially indistinguishable from Expt. 1. There are some differences between the experiments in the flux time series (Figures 9 and 12), but only in the last few days of the integrations. As the processes controlling shelf-break exchange and flow through Denmark Strait involve internal oceanic instabilities, it is unsurprising to eventually observe divergence of the experiments in this way. It is clear that the differences seen between the MM5 and the NCEP-forced experiments are almost entirely due to the higher spatial resolution in the MM5 product, however, and not the higher temporal resolution.

\subsection{North American Regional Reanalysis forcing}

Finally, we further explore the impact of spatial resolution in atmospheric forcing on the ocean model. In this respect, the North American Regional Reanalysis (NARR) is a useful product. This dataset has $32 \mathrm{~km}$ horizontal resolution and covers the period October 1978 to the present with 3-hourly output (Mesinger et al., 2006). It only extends over part of the western North Atlantic and eastern North Pacific Oceans, however. It covers $88 \%$ of our ocean model domain, with missing data northeast of Iceland, away from the area of greatest interest.

Experiment 5 uses NARR forcing with interpolation to NCEP values for the small region of missing data. Full results are not shown because the NARR-forced experiment is very close to Expt. 3, forced by NCEP data. For example, the Expt. 5 surface current speed and seasurface height distributions overlie those of Expts. 2 and 3 (not shown). The results for surface relative vorticity and divergence are also indistinguishable from the NCEPforced case. Compared to NCEP, the NARR fields show 


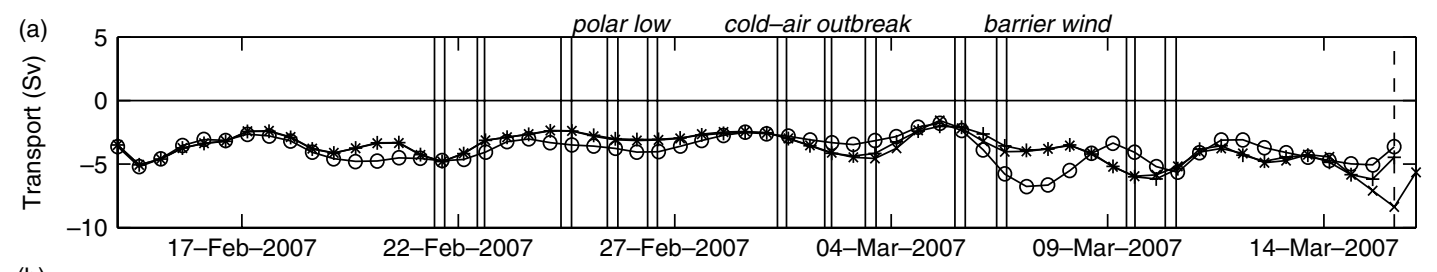

(i)
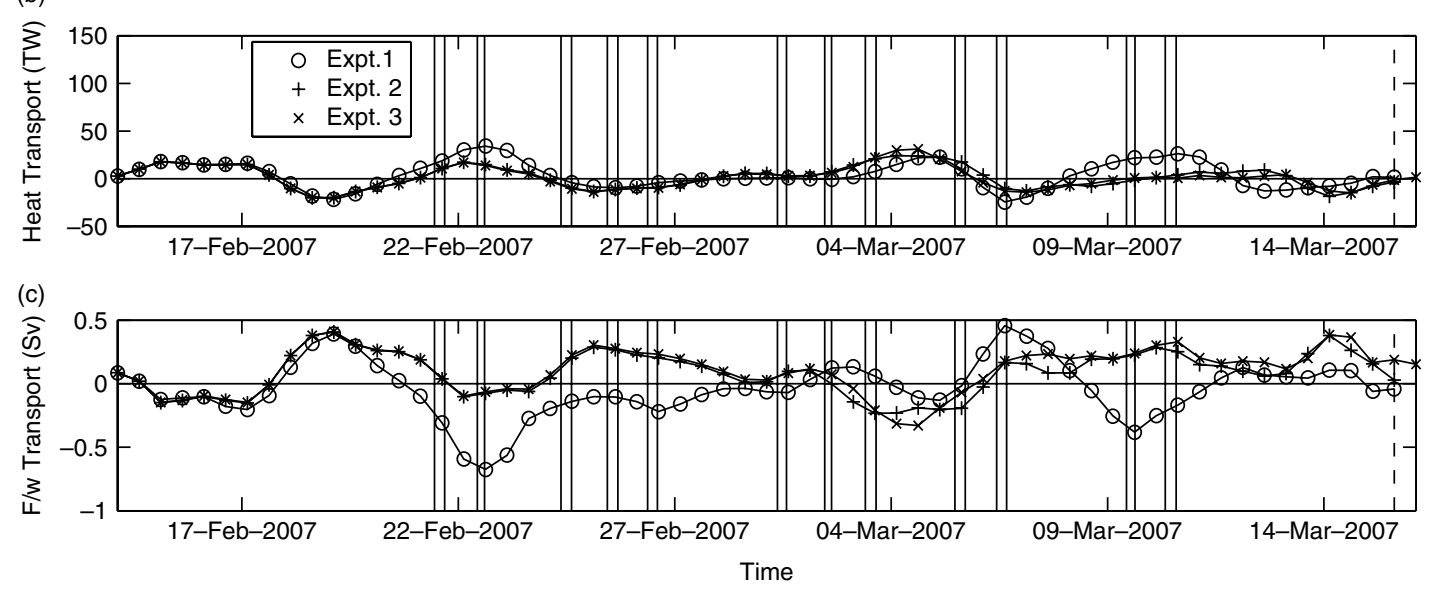

Figure 12. Time series of net fluxes across the Denmark Strait transect shown in Figure 1. Details are as in Figure 9.

higher-resolution features in wind speed, surface air temperature, and relative humidity, but they lack the intensities seen in the MM5 data. At 0300 UTC on 9 March 2007 (the time of Figure 2), the peak wind speeds for MM5, NCEP, and NARR are 28, 22, and $21 \mathrm{~m} \mathrm{~s}^{-1}$, respectively, for instance.

From these results, we conclude that the NARR fields are very similar to the NCEP fields in forcing Denmark Strait ocean circulation, despite being resolved eight times better. The implication is that processes simulated by MM5 at $12 \mathrm{~km}$ resolution, but missing from NARR data at $32 \mathrm{~km}$ resolution, are responsible for the MM5 versus NCEP differences. Another possibility is that the NARR winds are biased low.

\section{Summary and discussion}

The purpose of this article is to explore and quantify the impact of high-resolution, high-frequency air/sea forcing on the ocean circulation in the vicinity of Denmark Strait. The widely used NCEP 6-hourly, $2.5^{\circ}$ resolution global reanalysis product is compared to a custom regional atmospheric reanalysis using MM5 with hourly output and $1 / 10^{\circ}$ resolution. Our experiments are performed in a $2 \mathrm{~km}$ resolution regional ocean model with closed boundaries. There is no evidence that the results are compromised by the closed domain, and preliminary comparison with observations is encouraging (e.g. sea level; Figure 4). Indeed, important differences are revealed by the month-long winter simulations of ocean currents, hydrography, and sea ice forced by these meteorological data.

The model ocean circulation is sensitive to the difference between the MM5 and NCEP products in several upper-ocean diagnostics. This difference between MM5 and NCEP output is seen most obviously in the greater intensity and small-scale variability in the MM5 wind data (Figure 2). The surface air temperature, humidity, and precipitation fields are also significantly different. The response of the ocean model to the MM5 wind field is to increase current speed, kinetic energy, sea-surface height variability, and surface-ocean vorticity variability. This more vigorous circulation is clear in the time-average results (section 3.1, Table III) and the instantaneous fields during the strong barrier wind event of 9 March 2007 (section 3.2, Table IV, Figures 4 and 5). Similar results apply during the polar low of 25 February 2007, but with less striking differences (section 3.3). The upper-ocean boundary-layer thickness - reflecting the intensity of near-surface turbulent mixing - also shows a big difference between MM5 and NCEP forcing (Figure 6). Here, the effects of wind-generated turbulent mixing and stratifying surface rain compete to control the boundary layer, and the NCEP forcing drives deeper layers because the NCEP precipitation is much weaker and more diffuse than MM5's.

The thermodynamic response of the ocean model to the different forcing products is more muted. The surface water-mass structure of the ocean model responds to the different forcing fields (Figure 7), but the impact is relatively modest because the net air/sea heat fluxes are similar (Table III, Figure 3), and the experiments last only for one month. There is negligible impact of the highresolution MM5 forcing on average temperature, salinity, or baroclinic potential energy (Tables III and IV).

The response of the sea ice in the ocean model depends on both mechanical and thermodynamic forcing. Both the intense MM5 wind and the low NCEP air temperature and humidity promote large ocean heat loss (section 3.4). Consistently, the MM5-forced experiment has similar, but lower, sea-ice volume than the NCEP-forced experiment 
(Figure 8). The sea ice results also point to two other issues that are common to both the MM5 and NCEP forced experiments. First, the synoptic-scale atmospheric conditions have an important impact, as shown clearly by the increase in ice volume during the cold-air outbreak at the start of March 2007. Second, the ice volume declines overall, despite the persistent oceanic heat loss, indicating the importance of ocean mixing to the sea ice heat budget.

As for sea ice, the ocean fluxes across the east Greenland shelf break and through the Denmark Strait respond to the different forcing products in complex ways (section 3.5). For example, the more intense MM5 wind drives greater variability in volume, heat, and freshwater fluxes across the shelf break, but the other forcing fields have negligible impact (Figure 9). Moreover, volume flux changes account for most of the heat and freshwater flux variability. Although the wind field influences the shelf-break volume flux, there is no simple relation with the Ekman transport (Figure 11). At Denmark Strait, the high-resolution wind field also impacts the fluxes of volume, heat, and freshwater (Figure 12). As for the shelf-break section, the Denmark Strait transports are mainly controlled by internal ocean dynamics, however. The wind field can cause phase changes, and affect the variability, but the mean fluxes over one month are insensitive to the resolution of the atmospheric forcing in these experiments.

These findings show that the high-resolution MM5 product has a substantial impact on upper ocean circulation on time-scales of $\mathrm{O}(1)$ week. Comparison of NARRand NCEP-forced experiments suggests that atmospheric scales resolved at $12 \mathrm{~km}$ resolution by MM5, but absent from NARR data at $32 \mathrm{~km}$ resolution, are responsible for this impact (section 3.7). The high temporal resolution (hourly for MM5, 6-hourly for NCEP) is much less important (section 3.6). The main contribution of this article is to describe and quantify this impact. Clearly, ocean modellers should be aware of these effects when they choose to force their models with atmospheric products like the NCEP output used here. Unfortunately, O(10) km resolution meteorological reanalyses are not available on a routine basis for the global ocean for the last few decades.

Another important conclusion emerges from this study: physical consistency of the atmospheric forcing fields is critical for accurate ocean simulation. The results demonstrate this in two ways. First, it is key to use the atmospheric state $(10 \mathrm{~m}$ wind speed, surface air properties, and radiative fluxes), rather than the air/sea fluxes computed from the meteorological analysis, to force the ocean model. This finding has been reported before (Pagowski and Moore, 2001; Renfrew et al., 2002), because of biases in the air/sea flux algorithms used in atmospheric reanalysis models. But Figure 3 shows how the ocean/sea-ice model controls the net air/sea fluxes, particularly near the ice edge. Physical inconsistencies between the position of the ice edge in the reanalysis model and the ocean model will therefore cause large errors, if the ocean model is forced with the reanalysis air/sea fluxes. Second, Figure 6 shows how the ocean boundary-layer thickness is affected by wind-induced mechanical mixing and rain-induced buoyancy forcing. Physical inconsistency between the wind field and the precipitation field (as in Expt. 2) thus leads to large bias in the boundarylayer thickness (Figure 6(b)). Although using multiple sources for the atmospheric forcing fields is tempting, the resulting physical inconsistency may lead to large errors, as in Expt. 2. Of course, there exists some inconsistency in the present experiments because the ocean and atmosphere models are uncoupled. Quantifying this effect is left to future work, although it is probably minor compared to the MM5/NCEP differences as the ocean model resolves the large-scale sea-surface temperature field accurately.

The GFDEx campaign, and the availability of the highresolution MM5 reanalysis, offered an exceptional opportunity to study the impact on the ocean of small-scale, intense atmospheric forcing over the Denmark Strait. The question of how to extend the present results to longer periods, other regions, and coarser ocean model resolution naturally arises. On this topic, we can only speculate at this time. Over longer periods, the differences in air/sea buoyancy forcing will accumulate and cause changes in the hydrographic structure of the ocean model. The $6 \%$ difference in mean air/sea heat flux between Expts. 1 and 3 in Table III will take several years to drive large hydrographic changes, however, assuming that the present results can simply be extrapolated. Other regions, such as deep-convection sites, will be more sensitive to this effect. (Note that the intermittent deep-convection site in the southern Irminger Sea (Pickart et al., 2003) is not well represented in our ocean model, because of the nearby boundary.) The broader-scale impact of the lateral flux differences across the shelf break and through Denmark Strait (Figures 9 and 12) are also unclear because longer experiments are needed. The fact that the atmospheric forcing is only an indirect factor controlling these fluxes, and the net differences are quite small, suggests that long periods might be needed for significant impact to accumulate. For other regions, the present results probably provide an upper limit on the differences to be expected. The reason is that the GFDEx targeted intense, smallscale atmospheric conditions, that are inevitably missing from coarse-resolution products like the NCEP global reanalysis data. For coarser-resolution ocean models, the impact of the high-resolution atmospheric forcing will decline as the ocean model resolution becomes coarser and smears out the energetic $\mathrm{O}(10 \mathrm{~km})$-scale forcing features. Of course, the impact of degraded resolution on the internal ocean dynamics will also be profound, particularly when the internal deformation radius is no longer resolved.

\section{Acknowledgements}

The GFDEx was supported by the Natural Environmental Research Council (NE/C003365/1), the Canadian Foundation for Climate and Atmospheric Science, the 
European Fleet for Airborne Research, and the European Coordinated Observing System. TWNH was supported from NASA (MAP/04-0143-0073), NSF (OCE0326670, OCE-0726393), the Visiting Scientist Program of the Atmospheric and Oceanic Sciences Program, Princeton University, and the NOAA Geophysical Fluid Dynamics Laboratory. Alistair Adcroft kindly helped to configure the ocean model. The atmospheric reanalysis data were provided by the NOAA Earth System Research Laboratory and the NOAA National Climatic Data Center. Santha Akella helped prepare the NARR fields and data to compare with the ocean model. The altimeter products were produced by Ssalto/Duacs and distributed by AVISO, with support from CNES (http://www.aviso.oceanobs.com/duacs/)

\section{References}

Adcroft A, Campin J-M. 2004. Rescaled height coordinates for accurate representation of free-surface flows in ocean circulation models. Ocean Modelling 7: 269-284.

Adcroft A, Hill C, Marshall J. 1997. Representation of topography by shaved cells in a height coordinate ocean model. Mon. Weather. Rev. 125: 2293-2315.

Bacon S, Myers PG, Rudels B, Sutherland DA. 2008. Accessing the inaccessible: Buoyancy-driven coastal currents on the shelves of Greenland and Eastern Canada. In Arctic-Subarctic Ocean Fluxes, Dickson RR, Meincke J, Rhines P (eds). Springer-Verlag: Dordrecht. pp 703-722.

Bonjean F, Lagerloef GSE. 2002. Diagnostic model and analysis of the surface currents in the tropical Pacific Ocean. J. Phys. Oceanogr. 32: $2938-2954$.

Bromwich DH, Cassano J, Klein, Heinemann G, Hines K, Steffen K, Box JE. 2001. Mesoscale modeling of katabatic winds over Greenland with the Polar MM5. Mon. Weather Rev. 129: 2290-2309.

Bruce JG. 1995. Eddies southwest of the Denmark Strait. Deep Sea Res., Part I 42: 13-29.

Campin J-M, Adcroft A, Hill C, Marshall J. 2004. Conservation of properties in a free-surface model. Ocean Modelling 6: 221-284.

Cassano JJ, Box JE, Bromwich DH, Li L, Steffen K. 2001. Evaluation of Polar MM5 simulations of Greenland's atmospheric circulation. J. Geophys. Res. 106: 33867-33890.

Dickson B, Dye S, Jónsson S, Köhl A, Macrander A, Marnela M, Meincke J, Olsen S, Rudels B, Valdimarsson H, Voet G. 2008. The overflow flux west of Iceland: Variability, origins and forcing. In Arctic-Subarctic Ocean Fluxes, Dickson RR, Meincke J, Rhines P. (eds.) Springer-Verlag: Dordrecht. pp 443-474.

Dudhia J. 1996. 'A multi-layer soil temperature model for MM5'. Preprint for the sixth PSU/NCAR Mesoscale Model Users Workshop, 22-24 July 1996, Boulder, Colorado http://www.mmm.ucar.edu/mm5/lsm/soil.pdf.

Grell GA, Dudhia J, Stauffer DR. 1995. 'A description of the fifthgeneration Penn State/NCAR Mesoscale Model (MM5)'. Technical Report TN-398+STR, NCAR: Boulder, Colorado.

Haine TWN, Böning C, Brandt P, Fischer J, Funk A, Kieke D, Kvaleberg E, Rhein M, Visbeck M. 2008. North Atlantic deep water formation in the Labrador Sea, recirculation through the Subpolar Gyre, and discharge to the Subtropics. In Arctic-Subarctic Ocean Fluxes, Dickson RR, Meincke J, Rhines P. (eds.) Springer-Verlag: Dordrecht. pp 653-701.

Haine TWN, Marshall JC. 1998. Gravitational, symmetric and baroclinic instability of the ocean mixed layer. J. Phys. Oceanogr. 28: 634-658.

Hibler WD. 1980. Modeling a variable thickness sea ice cover. Mon. Weather Rev. 1: 1943-1973.

Hong S-Y, Pan H-L. 1996. Nonlocal boundary layer vertical diffusion in a medium-range forecast model. Mon. Weather Rev. 130: $1423-1432$.

Jackett DR, McDougall TJ. 1995. Minimal adjustment of hydrographic profiles to adverse static stability. J. Atmos. Oceanic Technol. 12: 381-389.
Jakobsson M, Cherkis NZ, Woodward J, Macnab R, Coakley BJ. 2000. New grid of Arctic bathymetry aids scientists and mapmakers. Eos 81: $89-96$.

Kain JS, Fritsch JM. 1993. Convective parameterization for mesoscale models: The Kain-Fritsch scheme. In Cumulus Parameterization. Meteorol. Monogr. 24: 165-170. Amer. Meteorol. Soc: Boston.

Kalnay E, Kanamitsu M, Kirtler R, Collins W, Deaven D, Gandin L, Iredell M, Saha S, White $\mathrm{G}$, Woollen J, Zhu Y, Chelliah M, Ebisuzaki W, Higgins W, Janowiak J, Mo KC, Ropelewski C, Wang J, Leetma A, Reynolds R, Jenne R, Joseph D. 1996. The NCEP-NCAR 40-year reanalysis project. Bull. Amer. Meteorol. Soc. 77: 437-471.

Käse RH, Girton JB, Sanford TB. 2003. Structure and variability of the Denmark Strait Overflow: Model and observations. J. Geophys. Res. 108: 1029/2002JC001548.

Käse RH, Oschlies A. 2000. Flow through Denmark Strait. J. Geophys. Res. 105: 28527-26546.

Large WG, McWilliams JC, Doney SC. 1994. Oceanic vertical mixing: A review and a model with non-local boundary layer parameterization. Rev. Geophys. 32: 363-403.

Large WG, Pond S. 1981. Open ocean momentum flux measurements in moderately strong winds. J. Phys. Oceanogr. 11: 639-657.

Large WG, Pond S. 1982. Sensible and latent heat flux measurements over the ocean. J. Phys. Oceanogr. 12: 464-482.

Lea DJ, Haine TWN, Gasparovic RF. 2006. Observability of the Irminger Sea circulation using variational data assimilation. $Q$. $J$. R. Meteorol. Soc. 132: 1545-1576.

Leith CE. 1968. Diffusion approximation for two-dimensional turbulence. Phys. Fluids 10: 1409-1416.

Marshall J, Adcroft A, Hill C, Perelman L, Heisey C. 1997. A finitevolume, incompressible Navier Stokes model for studies of the ocean on parallel computers. J. Geophys. Res. 102: 5753-5766.

Mesinger F, DiMego G, Kalnay E, Mitchell K, Shafran PC, Ebisuzaki W, Jović D, Woollen J, Rogers E, Berbery EH, Ek MB, Fan Y, Grumbine R, Higgins W, Li H, Lin Y, Manikin G, Parrish D, Shi W. 2006. North American Regional Reanalysis. Bull. Amer. Meteorol. Soc. 87: 343-360.

Moore GWK, Pickart RS, Renfrew IA. 2009. A climatology of the GFDEx observational period. Q. J. R. Meteorol. Soc. submitted.

Moore GWK, Renfrew IA. 2005. Tip jets and barrier winds: A QuikSCAT climatology of high wind speed events around Greenland. J. Climate 18: 3713-3725.

Pagowski M, Moore GWK. 2001. A numerical study of an extreme cold-air outbreak over the Labrador Sea: Sea ice, air-sea interaction, and development of polar lows. Mon. Weather Rev. 129: 47-72.

Petersen GN, Renfrew IA, Moore GWK. 2009. An overview of barrier winds off southeastern Greenland during the Greenland Flow Distortion experiment. Q. J. R. Meteorol. Soc. 135: 1950-1967.

Pickart RS, Spall MA, Ribergaard MH, Moore GWK, Milliff RF. 2003. Deep convection in the Irminger Sea forced by the Greenland tip jet. Nature 424: 152-156.

Pickart RS, Torres DJ, Fratantoni PS. 2005. The East Greenland spill jet. J. Phys. Oceanogr. 35: 1037-1053.

Renfrew IA, Moore GWK, Guest PS, Bumke K. 2002. A comparison of surface layer and surface turbulent flux observations over the Labrador Sea with ECMWF analyses and NCEP reanalyses. J. Phys. Oceanogr. 32: 383-400.

Renfrew IA, Moore GWK, Kristjánsson JE, Ólafsson H, Gray SL, Petersen GN, Bovis K, Brown P, Fore I, Haine T, Hay C, Irvine EA, Oghuishi T, Outten S, Pickart RS, Shapiro M, Sproson D, Swinbank R, Woolley A, Zhang S. 2008. The Greenland Flow Distortion Experiment. Bull. Amer. Meteor. Soc. 89: 1307-1324.

Renfrew IA, Petersen GN, Sproson DAJ, Moore GWK, Adiwidjaja H, Zhang S, North R. 2009. A comparison of aircraft-based surfacelayer observations over Denmark Strait and the Irminger Sea with meteorological analyses and QuikSCAT winds. Q. J. R. Meteorol. Soc. 135: 2046-2066.

Ross CK. 1977. Overflow-73 - Denmark Strait, Vol. 2: Moored Instrument Time Series. Technical Report Data Series/BI-D-77-5, Bedford Inst. Oceanogr. Dartmouth, NS, Canada, B2Y-4A2.

Rudnick DL. 2001. On the skewness of vorticity in the upper ocean. Geophys. Res. Lett. 28: 2045-2048.

Stark JD, Donlon CJ, Martin MJ, McCulloch ME. 2007. OSTIA: An operational, high-resolution, real-time, global sea surface temperature analysis system. In Oceans '07 IEEE Aberdeen. Marine 
challenges: Coastline to deep sea. Aberdeen, Scotland. DOI: 10.1109/OCEANSE.2007.4302251.

Tao WK, Simpson J. 1993. The Goddard cumulus ensemble model. Part I: Model description. Terr. Atmos.Ocean Sci. 4: 35-72.

Tao W K, Simpson J, McCumber M. 1989. An ice-water saturation adjustment. Mon. Weather Rev. 17: 231-235.

Våge K, Pickart RS, Moore GWK, Ribergaard MH. 2008. Winter mixed-layer development in the central Irminger Sea: The effect of strong, intermittent wind events. J. Phys. Oceanogr. 38: 541-565.
Zängl G. 2002. An improved method for computing horizontal diffusion in a sigma-coordinate model and its application to simulations over mountainous topography. Mon. Weather Rev. 130: 1423-1432.

Zhang J, Rothrock D. 2000. Modeling Arctic sea ice with an efficient plastic solution. J. Geophys. Res. 105: 3325-3338.

Zhang J, Schmitt RW, Huang RX. 1999. The relative influcence of diapycnal mixing and hydrologic forcing on the stability of the thermohaline circulation. J. Phys. Oceanogr. 29: 1096-1108. 